\title{
Cambios políticos, sociales y económicos en relación a la pesca y extracción del guano en la costa de Arica y Tarapacá: siglos XVI a inicios del XIX
}

\section{Political, social and economic changes in relation to fishing and extraction of guano on the coast of Arica and Tarapacá: sixteenth to early nineteenth century}

Jorge Hidalgo $^{1}$ https://orcid.org/0000-0002-0804-6391

Priscilla Cisternas $^{23}$ https://orcid.org/0000-0001-8858-0289

Julio Aguilar ${ }^{45}$ https://orcid.org/0000-0002-6267-4751

\author{
${ }^{1}$ Departamento de Ciencias Históricas, Universidad de Chile, Santiago, CHILE. Email: hidalgol@uchile.cl. \\ ${ }^{2}$ Centro de Estudios Históricos, Universidad Bernardo O’Higgins, Santiago, CHILE. \\ Email: pricecisa@gmail.com \\ ${ }^{3}$ Graduate Program History Department, University of California, Davis. Davis, USA. \\ Email: pricisternas@ucdavis.edu \\ ${ }^{4}$ Centro de Estudios Históricos, Universidad Bernardo O’Higgins, Santiago, CHILE. \\ Email: hidalgoaguilar@gmail.com \\ ${ }^{5}$ Graduate Program History Department, University of California, Davis. Davis, USA. \\ Email: julaguilar@ucdavis.edu
}

\section{Resumen}

El litoral del desierto de Atacama ha sido una fuente de obtención de energía importante y un medio para la vida social de las poblaciones prehispánicas y coloniales. Peces, mariscos y mamíferos marinos fueron productos claves en la dieta humana, a lo que se sumó el guano en los intercambios económicos y simbólicos y en el desarrollo agrícola. Tales actividades depredadoras y de recolección impulsaron la utilización de tecnologías e instrumentos para su acceso y tráfico, que reflejan procesos sociales de complejas organizaciones políticas y desarrollo cultural. El acceso y explotación de estos recursos marítimos estuvieron supeditados a los cambios políticos globales o imperiales que atravesaron los espacios andinos y americanos. Este artículo ofrece un panorama documentado de las transformaciones ocurridas en el ámbito de la explotación marítima desde el Tawantisuyu hasta fines de la era colonial e inicios del siglo XIX. Analiza los procesos de adaptaciones y las relaciones de dominación que implicaron las actividades extractivas de la costa del actual norte de Chile desde una perspectiva etnohistórica de larga duración.

Palabras claves: sociedades indígenas, guano, pesca, cambios políticos.

\begin{abstract}
The littoral of the Atacama Desert (North of Chile, South America) has been a source of energy and an environment relevant to the social life of prehistoric and colonial populations. Fish and other seafood were key products in the human diet. Moreover, guano (a natural fertilizer of marine origin) was also crucial for agricultural development and economic and symbolic interchanges. Hunting and collecting seafood encouraged the use of technologies and tools. These activities are reflected in the existence of complex political organizations and cultural development. Access to marine resources depended on global or imperial political changes occurring in the Andean and American social landscape. This article offers an overview based on historical sources related to the transformations in the marine economic exploitation from the Tawantinsuyu (Inca rule) to late colonial times and the early nineteenth-century. This article analyses, from an ethnohistorical point of view, the process of human adaptation, as well the relationship of power that were part of the extraction activities in the marine landscape.
\end{abstract}

Keywords: Indigenous societies, guano, fishing, political changes. 


\section{El impacto de las transformaciones políticas en la explotación marítima}

Las poblaciones prehispánicas y posteriores que habitaron el litoral del actual norte chileno hallaron en los productos marítimos como pescados, guano, mariscos y algas una fuente extraordinaria, permanente y abundante para su desarrollo económico, social y político (Figura 1). La ocupación y explotación de este amplio sistema ecológico puede plantearse positivamente desde una perspectiva de larga duración. Vale decir, observando la relación de los grupos humanos con el ambiente marítimo como un tipo de interacción estable, en el que las sociedades tras la conquista del mar por medio de múltiples innovaciones culturales lograron obtener una permanente fuente de subsistencia alimentaria, así como excedentes de otros productos o materias primas.

La corriente fría de Humboldt rica en oxígeno y las surgencias que traían nutrientes desde el fondo marino posibilitaron las condiciones para una cadena alimenticia de plancton, algas, moluscos, aves y mamíferos marinos que aportaron recursos renovables para las sociedades humanas. A la vez, la sequedad que se generó por la corriente mencionada y los vientos alisios permitieron la dominancia del desierto y la conservación, así como acumulación del guano de aves en la costa e islas cercanas durante milenios (Craig, 1982).

La gran profundidad histórica que posee la explotación del mar por parte de las sociedades del desierto de Atacama no debe oscurecer, sin embargo, las múltiples alteraciones que sucedieron a raíz de las distintas experiencias políticas de dominación o colonización del territorio. Transformaciones que implicaron la introducción de actores y lógicas de explotación, repercusiones en el acceso y usos, conflictos interétnicos, así como, posiblemente, cambios en la ideología o regímenes de significación social detrás de la extracción marítima.

\section{Antecedentes etnohistóricos tempranos}

La ocupación del mar por las sociedades prehispánicas está registrada en múltiples fuentes desde los períodos más tempranos (Larraín, 1978; Llagostera, 1979, 1989, 1993; Bittman, 1986; Núñez, 1986; Hidalgo et al., 1989; Falabella et al., 2016). Estudios antropológicos basados en el análisis de isótopos de restos humanos han confirmado que la obtención y consumo de proteínas marinas fueron significativos en la variada dieta de las poblaciones prehispánicas del norte de Chile, y que los productos marinos formaron parte de un intenso intercambio regional y flujo alimentario que incluía grupos costeros y altiplánicos (Pestle et al., 2015). Lo que nos interesa destacar acá es la relación de estas sociedades, especialmente las tardías preinca, inca y colonial temprano con el ejercicio de la pesca y la extracción del guano en las transformaciones sociales de esas comunidades.

Hasta época relativamente reciente se pensaba que los pescadores de la costa del Pacífico eran grupos más primitivos o atrasados que los pueblos propiamente agricultores de las civilizaciones andinas. Sin embargo, ya en 1946 J. Bird había planteado dudas ante las evidencias prehispánicas en la costa de Arica. Willey (1971) pensó que los changos no eran un grupo étnico independiente y que serían el resultado del empobrecimiento de los atacameńos, es decir, el resultado de un proceso colonial. Lizárraga (1987 [1603-9], p. 149) a inicios del siglo XVII describió a los pescadores desde Atacama a Copiapó como pescadores huidos hacia caletillas que les servían de refugio, con agua salobre y escasa, "pobres y casi desnudos", vestidos con pieles de lobos marinos y bebiendo de la sangre de estos mamíferos, carentes de productos agrícolas. Esta visión ha sido paulatinamente transformada por la investigación arqueológica y etnohistórica.

M. Rostworowski (1986) propuso la existencia de un "suyo" o provincia preinca compuesta por dos grupos étnicos, coles y camanchacas, que se extendía por tierras cálidas o yungas desde Camaná hasta Tarapacá. Los coles eran agricultores que ejercieron el predominio de sus autoridades sobre los caciques pescadores. Estos pobladores yungas habrían sido dominados por los pueblos serranos desde el Intermedio Tardío (1000-1450 DC aprox.), por carecer de poder frente al volumen demográfico de los pueblos de tierras altas. A. Llagostera (1976; 1979; 1989; 1993), con numerosas contribuciones 


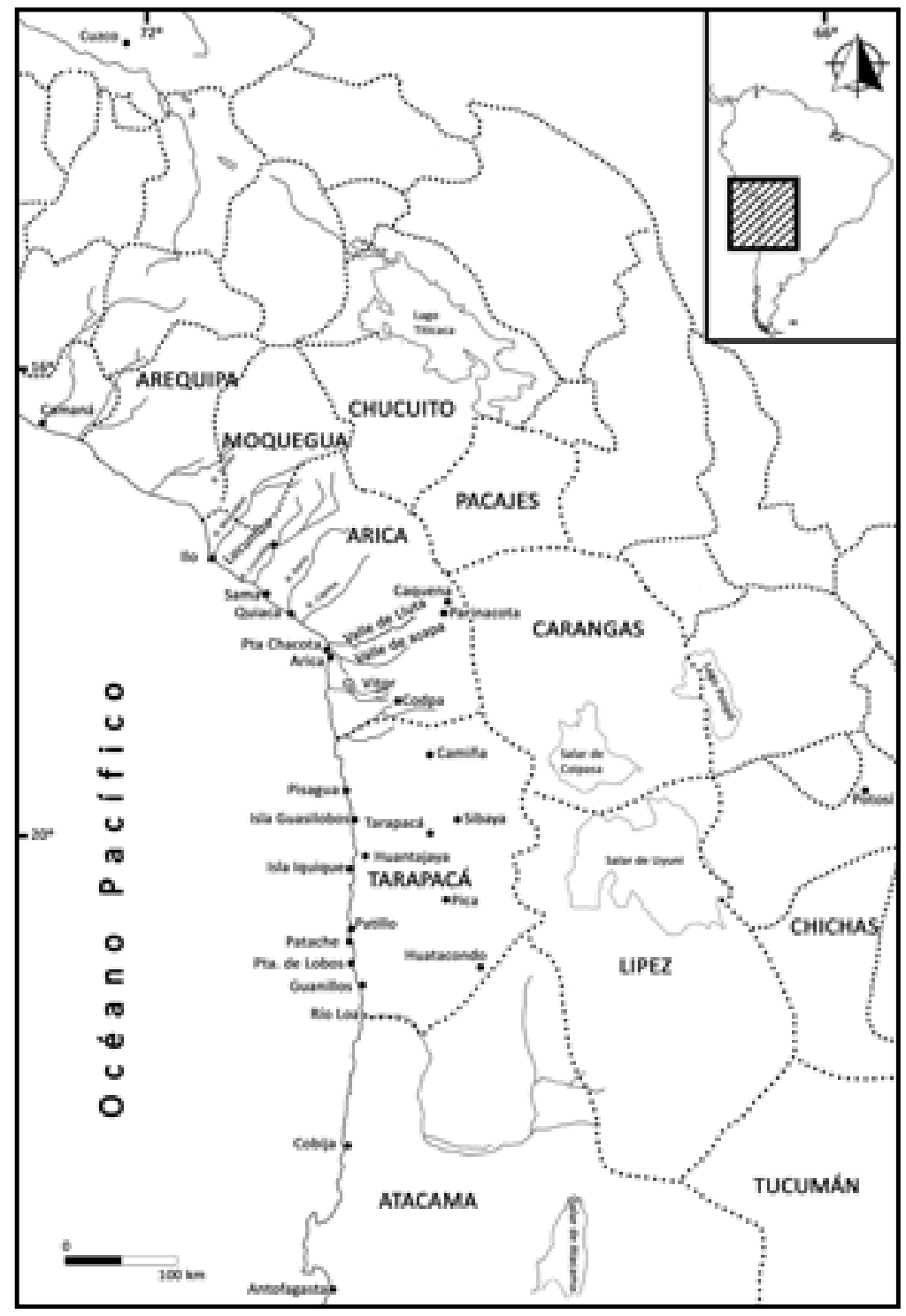

Figura 1. Cartografía esquemática de la región de estudio.

importantes sobre este tema, investigó tanto las relaciones entre los seńoríos altiplánicos con la costa como las grandes etapas de la conquista del mar a través de miles de años, mostrando las innovaciones tecnológicas que alcanzaron y la producción de excedentes en pesca que les posibilitó un nivel de vida muy lejos de la pobreza descrita en tiempos del dominio europeo. Documentos coloniales tempranos indican que los camanchacas de Arica no estaban en situación de subordinación de los agricultores, y que el cacique Pedro Chaco poseía tierras agrícolas en el valle de Azapa (Hidalgo, 2004 [2003]).
Murra (1964) destacó la importancia de la extracción del guano para las poblaciones andinas, basado en la información contenida en la Visita de Chucuito (1567). Sin embargo, los análisis más especializados y con mayor valor explicativo del origen del alto estatus de los pescadores del Pacífico en Arica y Tarapacá provienen de las investigaciones de Julien (1985) sobre la importancia del guano para los agricultores altoandinos desde tiempos preincas. La necesidad de su uso implicó relaciones entre esos grupos y los pescadores que tenían la posibilidad de extraerlo de las islas en las costas del Pacífico gracias al dominio 
de técnicas de navegación oceánicas. Catherine Julien planteó los problemas centrales en las relaciones entre los agricultores de las tierras altas y los pescadores del Pacífico: "Para la gente que vivió en las región que rodeaba el lago Titicaca, los recursos de las tierras bajas adyacentes fueron particularmente importantes" (Julien, 1985, p.185, traducción nuestra). Gran cantidad de gente vivía en los límites de la agricultura donde los desastres eran frecuentes. Ellos requerían de productos suplementarios como el maíz y estaban preparados para bajar e instalarse a cultivar por ellos mismos.

En esta zona seca, sin embargo, era necesaria la ayuda del guano como abono para incorporar a los suelos nitrógeno y fósforo que permitieran alcanzar altos niveles en la producción agrícola, y que las plantas pudieran aprovechar mejor la escasa cantidad de agua. Otro elemento indispensable era contar con los camélidos de carga, que era la riqueza de los altiplánicos, con los cuales establecieron relaciones económicas y circuitos caravaneros desde la costa, pasando por sitios de cultivo en los valles y en la sierra, así como transportar los comestibles hasta sus lugares de origen. Julien (1985) menciona pueblos de Tarata que teniendo tierras y aguas, por carecer de suficientes llamas no obtenían las cantidades necesarias de guano y, en consecuencia, eran pobres.

El acceso altiplánico a la costa adquirió dos formas, una centralizada y otra descentralizada. Esta última de muy larga duración que ha sido el acceso espontáneo, libre y directo de individuos o familias para atender sus necesidades de este fertilizante. Las tres etapas centralizadas que reconoce Julien son el período preinca, el inca y el colonial temprano. El primero corresponde a la expansión de los reinos lacustres. Entre ellos, a los collas, al norte del Titicaca, se les atribuye un enorme territorio que comprendía hasta el Cusco, Arequipa y por la costa hasta Atacama, según Sarmiento de Gamboa (Julien, 1985, p. 217). Cieza describe brevemente el conflicto entre collas y lupaqas; los últimos entran en alianza con los incas en expansión y los derrotan. ${ }^{1}$ Los incas

1 Cieza de León, P. (1986 [1553]), Crónica del Perú. Primera Parte. Capítulo C, p. 274. Estos episodios son ampliados por Cieza de León, P. Crónica del Perú. Segunda Parte. Capítulos XLI a XLIII, pp. 121-128. normalizan los derechos de los grupos étnicos a los recursos de las tierras bajas, distribuyen tierras de cultivo y aguas, también las fuentes del guano, por lo cual entregan dominio sobre islas guaneras. Este control queda radicado en los señores que envían mitimaes a la costa para obtener esos productos complementarios para sus comunidades. El tercer período, con información de 1567 , de la Visita de Chucuito, corresponde a un control centrado en los malkus en beneficio propio. Más tarde el guano se tornará, junto a la minería y la pesca en un lucrativo negocio de los hispanos. Otro factor de la fórmula para obtener guano era contar con gente de la costa que poseía la tecnología necesaria para llegar a lugares más alejados de esta. Los pescadores en sus balsas de madera o de cuero de lobos marinos se tornaron en un factor estratégico.

H. Horta (2015) ha profundizado el estudio de las relaciones entre agricultores y pescadores costeros y entre estos y los grupos altoandinos, concluyendo que los pescadores camanchacas conformaban un señorío que se extendía desde Punta de Chacota o Chacayuta, pasando por la Bahía Chacota hasta el pueblo y río Chacota en la desembocadura de la quebrada de Vítor, y que mantuvo relaciones de reciprocidad en un plano de igualdad con los agricultores costeros y altoandinos, coincidiendo en esto último con Santoro, Hidalgo y Osorio (1987).

De este modo Horta distingue a los camanchacas de Arica de aquellos de la costa de Atacama, así como de los uros altiplánicos trasladados a la costa en períodos tardíos y que en la época de Lucas Martínez Vegazo trabajaban en Lluta en tareas agrícolas. Sugiere además que las embarcaciones de los yungas pescadores o camanchacas en tiempos prehispánicos habrían sido las balsas de tres palos. En la época de la conquista y colonización aparecieron canoas de madera y luego se generalizaría la balsa de cuero de lobo. Estos cambios se habrían debido a la sobreexplotación de los bosques de maderas apropiadas por parte de los espańoles que agotaron ese recurso o también, diríamos nosotros, a la privatización de esos territorios.

Con la llegada de los españoles, se impuso otro tipo de dominio directo sobre tierra y costa y se rompió el virtual monopolio de los camanchacas en la 
navegación de la costa del Pacífico, obligándolos a servir con sus balsas a empresas españolas tanto en la extracción del guano como en su transporte. De modo que la explotación de pescado y guano es un instrumento para observar las relaciones de poder, no solo en las sociedades prehispánicas, sino también en el período colonial.

\section{Transformaciones coloniales del escenario marítimo. Siglos XVI-XVII}

La conquista europea del Nuevo Mundo generó un vasto proceso de transformación de los sistemas ambientales y vida de las sociedades americanas. Como parte de este proceso, la colonización hispana del espacio andino detonó una inédita transformación en la costa, escenario donde los grupos nativos padecieron prontamente los trastornos de la expansión occidental, viendo reducidos su espacio productivo y el número de su población (Cook, 1981, 2010). Durante las primeras décadas que siguieron inmediatamente al descubrimiento, fueron los encomenderos los encargados de explotar el mar y subordinar a los sectores indígenas. Posteriormente, en la década de 1570, se comenzó a configurar el espacio económico peruano que se encargó de reorientar definitivamente las actividades marítimas en el sur andino. La experiencia colonial, por tanto, implicará la introducción de nuevos actores y tecnologías, así como acomodos y luchas por el control y circulación de los bienes marítimos, como veremos, especialmente del guano.

Los primeros encomenderos procuraron explotar al máximo los recursos y mano de obra indígena que habitaba la costa. Para la empresa encomendera, el litoral y sus incipientes puertos y caletas fueron fundamentales para asegurar las comunicaciones entre los distintos repartimientos y actividades productivas. El guano extraído desde islas, roqueríos y cerros adyacentes al litoral fue fundamental para nutrir las tierras de las primeras iniciativas agrícolas hispanas, mientras que otros productos marinos abastecieron de alimentos la mano de obra de las faenas agrícolas y mineras. La costa del desierto de Atacama fue explotada por encomenderos como Lucas Martínez Vegazo y Jerónimo de Villegas en Arica y Tarapacá, y Juan Velásquez Altamirano en Atacama, quienes lograron articular el envío de pescado al naciente mercado colonial durante el siglo XVI. ${ }^{2}$ Como coincidirán algunos cronistas, muchos españoles se enriquecieron con las actividades marítimas.

El efecto de la colonización pudo ser diverso al interior de los grupos étnicos surandinos respecto al manejo de los recursos marítimos. Los kurakas de los reinos altiplánicos, por ejemplo, dispusieron de los recursos marinos y tierras de cultivo de la costa a título personal, utilizando para ello a mitimaes. Sin embargo, situación diferente habrían atravesado las unidades domésticas que se desplazaban hacia la costa en los años de sequía, buscando tierras donde cultivar y recurriendo a la extracción de guano para hacerlas productivas (Julien, 1985).

Las primeras referencias documentales para el caso de la encomienda de Lucas Martínez Vegazo demuestran que tempranamente los camanchacas fueron sometidos al poder del encomendero y sus oficiales, tal como señala una declaración proveída por Gonzalo Valencia, quien fuera el administrador de la encomienda.

Yten me descargo de diez hanegas de maíz que di a los camanchacas porque sacasen guano para la chacara que hicieron los dichos yanaconas en el dicho valle de Guaycalana de la cual se cogieron las ciento y veinte hanegas de que estoy hecho cargo.

Yten me descargo de cinquenta y cinco hanegas de maíz que di a los indios que llevaron agualne [agua en el] varco a las minas de $\mathrm{Hi}$ queyque del dicho Lucas Martinez en onze viajes a cinco hanegas cada viaje. ${ }^{3}$

2 Trelles, 1982; Hidalgo, J., 1981, 2014a; Téllez, E., 1986. Mayores referencias sobre Juan Velázquez en Archivo General de Indias, Charcas Legajo 80 transcrito por Martínez, J., Sanhueza, C., Odone, C. y Ruiz, A., 1992.

3 Causa de cuentas llevada contra Gonzalo de Valencia sobre la administración de la encomienda de Lucas Martínez Vegazo entre 1570 y 1571. Archivo General de la Nación, Lima-Perú, Derecho Indígena y Encomienda, Cuaderno 15, legajo 2, f. 418. Citado por Helena Horta, 2015, p. 56. Este documento fue originalmente ubicado por el primero de los autores en Lima. Agradecemos a 
Aun cuando la cita no es lo suficientemente explícita, observamos a los camanchacas extrayendo guano (¿de la costa de Arica?) para una chacra en Lluta, por lo que recibieron 10 fanegas de maíz y luego llevaron agua a las minas de Iquique, seguramente Huantajaya, en "varco" en once viajes, por lo que recibieron cinco fanegas de maíz en cada viaje, con un total de 55 fanegas. Creemos que el uso del término "barco" debe corresponder a balsas de cuero de lobo, pues no parece que los camanchacas hubieran adoptado barcos para su navegación, como hemos visto, y por otra parte la cantidad de viajes indica navíos que podían soportar bajo peso.

Los camanchacas de Arica, además de agua, llevaban pescado a las minas de Huantajaya, de acuerdo al testimonio de uno de los testigos de Gonzalo Valencia, Juan Martín Mulato, quien declaró:

\section{[...] a la decima pregunta dixo que save y via [veía] es que los dichos mayordomos tenian de costumbre dar coca a los yndios que an- davan trabajando en las minas de Yqueyque e a los indios camanchacas que trayan pes- cado e agua a las dichas minas sin por ello les llevar cossa alguna y lo mismo vio este testigo que hizo el dicho Gonçalo de Valen- cia todo el tienpo que fue mayordomo del dicho Lucas Martinez hasta que vino nueva que hera muerto. ${ }^{4}$}

Los camanchacas proveían de agua y pescado a los indios que trabajaban las minas de Huantajaya y traían guano a las chacras del encomendero en Lluta, a cambio de ello recibían maíz y coca, productos que como ha afirmado Horta “...ya no producían debido a la desarticulación de la vida económica nativa" (Horta, 2015, p. 57). Además de estos servicios personales, las poblaciones andinas bajo el sistema de encomienda debían entregar tributos, inicialmente en especies, aunque a medida que se fue incorporando el sistema monetario en los Andes, irá aumentando el porcentaje de metálico con que se cubría el tributo que era cancelado por las comunidades. De los recursos existentes en la costa, los indígenas encomendados en Tarapacá

Alan Durston la transcripción del microfilme.

4 Ibíd., f. 376. debían entregar por concepto de tasa hacia 1550 la cantidad de 150 arrobas de pescado y 15 cántaros de aceite de lobo (Trelles, 1982, pp. 195-196). Además, la lista incluyó alrededor de 13 productos tales como ropa de lana y algodón, maíz, trigo, aves domésticas, huevos, puercos, carneros, ovejas, llamas, cántaros, sebo, sal y algunos servicios personales. Hidalgo (2004 [2003]) llamó la atención sobre la gran cantidad de pescado seco que las poblaciones del sur entregaban como tributo en el siglo XVI, lo que probablemente obedecía a su conservación durante largo tiempo, lo que facilitaba su transporte y venta. Durante este período, una arroba de pescado seco se vendía a un peso. En las tierras altas, además, el pescado seco servía de elemento de intercambio equivalente al charqui (Trelles, 1982).

La necesidad de acceder a embarcaciones que realizaran el traslado de mercancías hacia los nacientes centros coloniales o a los puertos de conexión hacia el interior de las provincias altoandinas generó una alta demanda de recursos forestales utilizados en la construcción de estas embarcaciones. Esta situación no solo tuvo repercusiones en el paisaje, sino que además, modificó la construcción de embarcaciones tradicionales por parte de las comunidades indígenas. Como ha demostrado Horta (2015), las poblaciones costeras de Arica utilizaron en tiempos prehispánicos las balsas de tres palos, adoptando la construcción de balsas de cuero de lobos en la época colonial, debido a la deforestación que sufrieron los valles del Corregimiento de Arica por la explotación realizada por los europeos, quienes demandaron una gran cantidad de madera para la construcción de viviendas y embarcaciones.

El puerto de Iquique tempranamente fue utilizado para la recalada y salida de embarcaciones que contenían productos del interior y de la costa de la provincia. El encomendero de Tarapacá Lucas Martínez Vegazo dispuso de una embarcación después de octubre de 1540 que unía el puerto de Iquique y la costa de Tarapacá con los puertos de Chule, Quilca, Ilo y Arica, abasteciendo principalmente de alimentos y agua a las minas de Tarapacá. Probablemente en estos viajes la embarcación también fue utilizada en el trasporte de pescados y guano, recursos a los 
que tuvo acceso por medio de la encomienda. ${ }^{5}$ En 1548, la encomienda de Tarapacá estuvo en manos de Jerónimo de Villegas, quien compró la tercera parte de los derechos de una pequeña naviera, que con dos barcos y tripulación negra pescaba en las costas del sur del Perú, comercializando el pescado seco en la ciudad de Arequipa (Trelles, 1982, pp. 88-89; Lockhart y Schwartz, 1992, p. 97). La costa de Arica también sufrió importantes alteraciones con la fundación del pueblo de españoles, yanaconas y negros, y el alto tráfico de productos que experimentó su puerto debido al éxito alcanzado con la explotación de las minas altoandinas (Larraín, 1974). Todos estos factores, sin duda tuvieron repercusiones en el despoblamiento de la costa, removiendo a la población indígena que habitaba estos parajes hacia sectores más restringidos.

Como es sabido, las pretensiones señoriales de los encomenderos colisionaron con los intereses reales, proceso que culminó finalmente con la transformación de esta institución y la consolidación de los corregimientos. ${ }^{6}$ Lo que aquí interesa destacar es que, no obstante sus cambios, ciertos derechos desprendidos de la encomienda seguirán operando a lo largo de la época colonial como "pensiones de indios", así como el "arriendo" de puertos (Villalobos, 1979). El mecanismo funcionó como una subasta pública donde el mejor postor se adjudicaba el derecho a controlar puertos, islas e islotes de pesquerías y guaneras. ${ }^{7}$ Usando este mecanismo, varios empresarios montaron redes de tráfico marítimo cuyos beneficios debieron ser significativos. Basta ver el caso de Juan Donoso, vecino hispano de Pica y Tarapacá, quien pagó la suma de 1800 pesos anuales por el arriendo de los puertos de Iquique, Loa y Pisagua por un lapso de cuatro años al encomendero Pedro de Córdova y Mesia. ${ }^{8}$ A lo largo del siglo XVII y

5 Trelles, 1982, p. 50. Lucas Martínez Vegazo dispuso de distintos barcos para sus negocios y la administración de su encomienda. Véase Trelles, 1982, pp. 244-245.

6 No nos corresponde acá hacer una relación de la evolución de la encomienda y las políticas que fueron poniendo fin a sus pretensiones y el consiguiente progresivo aumento de poder de los corregidores. Véase Lohmann Villena, 2001.

7 Más detalle sobre el arriendo de los puertos, véase Villalobos, S., 1979; Hidalgo, J., 2014c [2011]; Aguilar y Cisternas, 2013; Cúneo-Vidal, 1977.

8 Además, Juan Donoso realizó un préstamo al enco- también del siguiente, el mecanismo de arriendo de puertos prevaleció para Iquique, Loa y Pisagua.

Como en otras esferas de la administración colonial, los ańos del gobierno del virrey Francisco Toledo (1569-1581) repercutieron en la vida económica y social de la costa. La reorganización del tributo indígena de los repartimientos de Tarapacá, Pica y Loa, así como Lluta y Arica, impusieron a las autoridades étnicas e indios del común, para asegurar el pago de una tasa, que además de piezas de algodón, aves de Castilla, fanegas de maíz y gallinas, incluyó pescado seco y salado.

[...] Tarapacá 278 arrobas de pescado seco de la mar cuatro tomines de la dicha plata cada arroba montan 139 pesos.

Pica y Loa 40 arrobas de pescado salado y seco a 4 tomines la arroba montan 20 pesos. Tasa de Lluta y Arica 80 arrobas de pescado seco a 4 tomines la arroba montan 40 pesos ensayados [...] (Cook, 1975, p. 237).

A contar del gobierno de Toledo, se buscó que los indígenas cancelaran su tasa principalmente en plata. Pese a estas indicaciones, sabemos que en el sur andes se mantuvo principalmente el pago del tributo en especies. Nuevamente se encuentran entre los productos tributados por los indígenas el pescado salado y seco.

Esta reorganización del tributo indígena formaba parte de la maduración de la política económica del colonialismo español en los Andes, cuyo pilar fue la reactivación de Potosí y otros centros mineros gracias al suministro de azogue y la mita, vale decir, el envío de mano de obra campesina para trabajar en las minas (Larson, 1988; Bakewell, 1989). Al alero de estos centros mineros y comerciales como Lima, el aumento de población fue forjando un mercado de consumo de alimentos y bienes que impulsó la producción e integración regional (Assadourian, 1979, 1982).

mendero por 2800 pesos. Archivo Histórico Nacional, Fondo Judicial de Iquique, causas civiles. Legajo 291, Pieza 1. Legalización del testamento de Juan Donoso, $\mathrm{f}$. 12r - f. 12v. Aguilar y Cisternas, 2013. 
Los corregimientos de Arica y Atacama con acceso al Pacífico fueron claves en el despliegue de este espacio económico. Desde el puerto de Arica ingresaba el azogue con dirección a los centros mineros de la Audiencia de Charcas como Oruro y Potosí, y salía la plata extraída de estos centros rumbo a la metrópolis espańola (Escobari, 1985). Por otra parte, también desde Arica se enviaban productos como pescado seco y salado al Alto Perú (Aguilar y Cisternas, 2013). La diversidad y abundancia de especies marinas disponibles en las costas del norte de Chile como sardinas, anchovetas, pejerreyes, tomollos y mojarras, además del congrio, tollo, corvina y jurel, entre otros, llamaron la atención de los cronistas hispanos (Vázquez de Espinosa, 1948 [1636], p. 1420). Esta variedad de recursos, sin duda influyó en que las costas de Arica, Tarapacá y Atacama formaran parte de uno de los núcleos pesqueros que abastecieron a Potosí y otras ciudades mineras altoandinas (Assadourian, 1982). La demanda de recursos extraídos desde la costa fue en aumento, registrándose en 1607 el envío a Potosí de 6 mil arrobas de pescado a un valor de 4 pesos la arroba, lo que daba un valor total de 24 mil pesos. ${ }^{9}$ Esta información nos permite dimensionar la importancia que habían adquirido los recursos marítimos. La situación influyó en que a inicios del siglo XVII, se articularan redes comerciales por parte de grupos hispanos como el cura Francisco Otal en Atacama, o Damián de Morales y Juan Donoso en Tarapacá (Hidalgo, 2011, 2014b, 2014c [2011]; Aldunate, Castro y Varela, 2010; Aguilar y Cisternas, 2013).

El pescado extraído era secado o salado para su traslado a las provincias del interior. ${ }^{10} \mathrm{La}$ carga fue llevada inicialmente por caravanas de llamas y luego en mulas. Las rutas comerciales tejidas durante los siglos XVI y XVII permitieron unir los puertos y caletas que formaban el Corregimiento de Arica con el centro y sur Andino, los Andes centrales y los Andes del Sur y las provincias del interior como Cusco, Potosí y Oruro; ${ }^{11}$ y en el caso del Corregimiento

9 Según datos de Marcos Jiménez de la Espada, citado en Escobari (1985).

10 Una revisión de los modos de conservación de los productos de la costa. Véase Rostworowski, 1981.

11 Los vecinos y dueños de mulas Bartolomé Núñez, Pedro de Aróstegui y Bernardo de Oviedo forman parte de algunos registros contenidos en el Fondo Notarial de de Atacama las recuas se dirigieron con las remesas de pescado a Potosí, Chuquisaca, Lipes y otras provincias cercanas. ${ }^{12} \mathrm{El}$ viaje efectuado en 1659 por Pedro de Aróstegui, dueño de mulares en la ciudad de Arica, permite ilustrar la circulación de los recursos marinos en el espacio económico peruano. Aróstegui recibió del tesorero de Arica Andrés Bueno "honce tercios de tollo que pesaron cinquenta $\mathrm{y}$ sinco arrovas dos tercios de congrio que pesaron quarenta y ocho arrovas [...] diez y seis tercios de corvina pesaron ciento y honce arrouas" ${ }^{13}$ En total, partió desde la ciudad de Arica con 200 arrobas de pescado hacia el Cusco, deteniéndose primero en los centros mineros de San Antonio de Esquilache y de Tina Molloco. El dinero obtenido de la venta de los recursos marinos lo invirtió comprando azúcar y cajas de conservas en el Cusco, con los cuales retornaría a Arica.

En suma, el funcionamiento del espacio económico peruano impulsó que en el Corregimiento de Arica vecinos hispanos se especializaran en la extracción y circulación de productos provenientes de la costa. Los indígenas tuvieron una importante participación en el funcionamiento de este mercado colonial. Algunos aparecen en los registros como consumidores de estos recursos, tal como el cacique de Sibaya, quien recibió remesas de pescados hacia 1637, adeudando por este producto y vino la cantidad de 100 pesos. ${ }^{14}$ Sin embargo, los grupos indígenas fueron

Arica que contiene el traslado de pescado y guano hacia el Cusco y el interior del Corregimiento a inicios del siglo XVII. Véase Archivo Histórico Nacional, Fondo Notarial de Arica, volúmenes 2 y 5 . Sobre la arriería en los Andes y su conexión con el desarrollo de los centros mineros altoandinos véase Glave, 1989; Medinacelli, 2010. Un reciente trabajo sobre las rutas de circulación comercial entre Arica y la Audiencia de Charcas en Choque y Múñoz, 2016.

12 De acuerdo a Vázquez de Espinosa (1948 [1636], p. 1752) en Atacama se realizaba "[...] grandissima pesca de congrios, tollos, lisas, dorados, armados, vagres, jureles, atunes, pulpos y otros muchos generos de pescados, que salpresan, y del se llevan grandes recuas de carneros a Potosí, Chuquisaca, Lipes, y a todas aquellas provincias de la tierra de arriba, por que es el trato principal de aquella tierra, con que han enriquecido muchos".

13 Archivo Histórico Nacional, Fondo Notarial de Arica, Volumen 5.

14 Archivo Histórico Nacional, Fondo Judicial de Iquique, causas civiles. Legajo 291, Pieza 1. Legalización 
principalmente empleados como mano de obra, constreñidos bajo el sistema de encomienda o como servidumbre de dueños de pesquería mediante el endeudamiento (Aguilar y Cisternas, 2013). Además de la extracción de los recursos marinos, participaron en su preparación (secado o salazón) y traslado hacia las provincias del interior y otros mercados coloniales. ${ }^{15} \mathrm{La}$ explotación de la costa no estuvo a cargo de población indígena, pues existen registros de otras castas o sectores subalternos de la sociedad local como esclavos negros y zambos reclutados para realizar actividades pesqueras. ${ }^{16}$ Además, los registros parroquiales de este período muestran la presencia de mestizos y españoles, quienes probablemente cumplieron funciones de mayordomos de encomiendas y/o empresarios a pequeña escala o trabajadores para otros en la explotación de estos recursos. ${ }^{17}$

El guano fue uno de los bienes costeros que cobró especial relevancia en el mercado interno colonial. Antes que fuera valorado en los mercados internacionales decimonónicos, este abono fue conocido y explotado en tiempos prehispánicos y reorientada su circulación durante el período colonial. Las costas del virreinato peruano albergaron gran cantidad de

del testamento de Juan Donoso, 1640.

15 El proceso de secado o salazón del pescado implicaba remover el agua contenida en el pescado impidiendo la reproducción de bacterias, cuyo resultado era un alimento con mayor capacidad de conservación. Esta función era realizada en muchas ocasiones por las mujeres y niños de los habitantes de la costa (Rostworowski, 1981).

16 Ya hemos mencionado a Jerónimo de Villegas (15481556) quien formó una compañía de pesca, con mano de obra esclava. El encomendero además mandató que los indios de su repartimiento debían abastecer con alimentos e instrumentos a los pescadores negros (Véase Trelles, 1982; Lockhart y Schwartz, 1992). El vecino de Arica Agustín del Castillo señaló que el zambo Agustín Perez le debía una cantidad de pesos que cancelaría con trabajo en una pesquería que tenía en el chinchorro, a media legua de la ciudad. Archivo Histórico Nacional, Fondo Notarial de Arica, Volumen 5, s/f.

17 A inicios del siglo XVII se inicia una investigación en la ciudad de Arica por la repentina muerte de dos espańoles, Lorenzo Báez y Benito González, marineros de la Armada que fallecieron sin dejar testamento, ahogados en el puerto de Arica "andando pescando" debido a que habían iniciado una compañía. Archivo General de Indias, Casa de Contratación 498B, N ${ }^{\circ}$. Bienes de Difuntos de Lorenzo Báez y otros, 1606. guano, pero particularmente el guano proveniente de Iquique fue reconocido por distintos testigos coloniales por sus altas cualidades como fertilizante. Según el relato de Cieza de León (1986 [1553], p. 222) en los valles de Tarapacá, cerca del mar, existía una isla donde "[...] los naturales van a ellos en balsas y de las rocas que están en sus altos traen gran cantidad de estiércol de las aves para sembrar sus maizales y mantenimientos, y hállanlo tan provechoso que la tierra se para con ello muy gruesa y fructífera”. En 1630, López de Caravante expresó su admiración por las cualidades del guano en la región.

[...] está una isla que llaman de Yqueyque, en donde se recogen infinidad de pájaros, de cuyos excrementos se hace un estiércol que se llama guano en lengua de los indios, con que se siembra el trigo y maíz y las otras legumbres, todo á mano, como las habas en Castilla; y echando un puño dél en cada ordinario cogen 300 hanegas y más, y vez hubo que se cogieron $500 .^{18}$

Además del guano de Iquique, también se encontraba este abono en las cercanías de Arica. Lizárraga (1987 [1603-08], p. 146) observó la presencia de guano advirtiendo que "la playa de Arica es muy grande y muy conocida por un morro (así lo llaman los marineros) blanco que de muchas leguas en la mar se parece. Es blanco por respecto de los muchos pájaros que en él vienen a dormir, cuyo estiércol le ha vuelto tal". Las mejores descripciones están en Vázquez de Espinosa y aun cuando es muy conocida vale la pena reproducirla en este contexto:

Ay en esta tierra vna rica mina, que es el remedio de todos; y muchos se han enrriquezido con ella, y su trato; y es que en esta tierra todo el trigo, mais, y demas cosas que se siembran, para que produsgan con fertilidad, y ventaja las guanean, que es lo mismo que estercolar, antes de sembrar, y despues de sembrado; y es que 40 leguas de esta ciudad,

18 Jiménez de la Espada. 1965. Relaciones Geográficas de Indias, publícalas el Ministerio de Fomento, Perú. Tomo I, Apéndice Núm. II. López de Caravantes, pp. CXXXVIII. Not. Gener. del Perú y Tierra Firme, etc. Ms. Madrid: Atlas. 
[Arica] cerca de Tarapaca a vista de tierra está vn islote pequeño, donde van muchas fragatas a cargar de la tierra del dicho islote, que es amarilla, algo blanquisca, y el olor de marisco, y no muy pezada a la qual llaman guano, y la cargan en fragatas a la dicha ciudad, y a todos los puertos, y valles; y la venden por hanegas, que ordinariamente vale la hanega a 12 Reales y a 14 y todos los labradores la compran para sus sembrados, y los indios la llevan en sus carneros, de suerte que primero dexaran de comer, que de comprar guano, porque guaneando vna hanega de sembrado de ordinario da 300, 400, 500 hanegas... y los indios que no alcançan de este, lo van a buscar entre las peñas a la marina, pero a muchos a enrriquezido que an andado al trato del con fragatas (Vázquez de Espinosa, 1948 [1636], p. 1418).

La historia colonial de la extracción y circulación del guano permite vislumbrar el grado de interrelación entre la costa y las tierras interiores, entre el litoral y el desarrollo de la agricultura andina y de la hacienda hispana. Las propiedades fertilizantes del guano lo transformaron en un producto apetecido por los hacendados hispanos que deseaban aumentar la producción de sus tierras, especialmente de aquellos productos que eran comercializados en los centros mineros y las grandes urbes coloniales. ${ }^{19}$ La producción de ají sirve para observar la importancia de este abono. Este producto fue altamente apreciado y consumido en Potosí y Oruro. ${ }^{20} \mathrm{Su}$ cultivo se realizó en los valles de Sama, Locumba, Tacna y Arica, en la franja costera del Obispado de Arequipa. El cultivo de ají en el valle de Azapa, en Arica, fue favorecido por las buenas condiciones de la tierra y porque era abonada además con guano. ${ }^{21}$

19 Vázquez de Espinosa (1948 [1636], p. 1418) enfatizó que gracias al guano Gonzalo de Valencia logró sembrar "8 almudes, o celemines de trigos en macollas como se siembran las habas, y guaneando, cogío de ellos 1000 fanegas".

20 Vázquez de Espinosa (1948 [1636], p.1412) en referencia a los valles de Lucumba y Sama seńala: "En este valle y en el pasado se siembra mucho pimiento que alla llaman agi, y se cogen en los dos cerca de doscientos mil cestos que sacan en carneros para Potosí y Horuro".

21 Sobre la producción agrícola de este valle, consúltese
Por tal razón, la explotación del guano comenzó a generar el enriquecimiento de algunos europeos, al punto que -como hemos visto- Vázquez de Espinosa (1948 [1636], p.1419) lo consideró "una mina que es el remedio de todos". Mientras que mano de obra indígena extraía el guano para los empresarios y arrendatarios de puertos e islas, en la sierra los indios debían trabajar en las tierras de otros sectores del poder colonial. Este fue el caso de los indios de Tarapacá que en 1620 estaban obligados a "guanear" las tierras que les había usurpado un doctrinero (Hidalgo, Díaz y Cisternas, 2014 [1985]).

En los registros notariales podemos apreciar la participación de dueños de mulas y prestamistas de la ciudad de Arica en el comercio del guano. Por ejemplo, en 1620 Pedro Quintero debía a Gonzalo y Manuel Maraver la suma de "setecientos y ochenta y siete pesos corrientes de a ocho reales y medio peso mas los quales le debo y son por razón de otra tanta cantidad que montaron seicientas fanegas de guano que me vendió a diez reales y medio cada fanega”. ${ }^{22} \mathrm{O}$ el dueño de mulas Bernardo de Oviedo, quien entregó un poder para que en su nombre se remataran "quienientos y veinte y dos fanegas de guano a once reales". ${ }^{23}$ Incluso, no resulta extraño que los curas de la provincia hayan estado involucrados en este lucrativo negocio. Por ejemplo, el clérigo de la ciudad de Arica Juan del Pozo detalló en su codicilio que adeudaba al capitán Roque de Otarola la suma equivalente a "sinquenta o setenta fanegas de guano" que solicitó para Michaela de Yzaguirre. Además, también le debía a este capitán dos arrobas de congrio salado. ${ }^{24}$

Desde el siglo XVI, pero con propiedad en el siguiente siglo, el proceso de colonización modificó entonces de manera sustancial la fisonomía social y

Álvarez, 2014. Vázquez de Espinosa (1948 [1636], p. 1665) menciona que desde Arica suben hacia Potosí "el pimiento, que llaman ucho". Antecedentes sobre la producción del valle de ají y otros productos en el valle de Azapa, véase Hidalgo, 1993; Henríquez, 2003.

22 Archivo Histórico Nacional, Fondo Notarial de Arica, Volumen 2, 1620, s/f.

23 Archivo Histórico Nacional, Fondo Notarial de Arica, Volumen 2, 1620.

24 Archivo Histórico Nacional, Fondo Notarial de Arica, Volumen 2, 1699, s/f. Codicilio del clérigo de Arica Juan del Pozo. 
económica de la costa. Si bien en algún nivel los grupos indígenas siguieron teniendo acceso a la abundante riqueza marina, sectores estratégicos como los depósitos de guano más ricos y puertos fueron controlados por grupos dominantes hispanos. ${ }^{25}$ Los embates de la colonización se aprecian también en el funcionamiento de estos puertos y la burocracia política y fiscal de corregidores y cajas reales, en el ingreso y egreso de productos americanos y no americanos, así como el tráfico mular hacia Potosí y otros centros mineros. ${ }^{26}$ Esta situación generó también la atracción de piratas y corsarios que arribaron en numerosas ocasiones a las costas del actual norte de Chile, obligando a la instalación de cañones y armadas para su resguardo. A mediados del siglo XVII el piloto mayor Manuel Rodríguez, de origen portugués y radicado en Arica, negoció con el virrey Mancera para que se le concediera la nacionalidad castellana a cambio de restaurar el fuerte y las defensas del puerto de Arica con sus propios recursos. ${ }^{27}$ Paralelamente se ponían vigías indígenas en puntos altos de la costa por si aparecían barcos enemigos (Dagnino, 1909, pp. 134-135).

25 Vázquez de Espinosa (1948 [1636], p. 1418) destacó en su descripción de Tarapacá la existencia de un auxilio para los pobres indígenas de la jurisdicción proveniente de la costa. Relató que abundaban grandes cardúmenes de pescados durante los meses de febrero y marzo, que empujados a la costa por otros peces mayores, lobos marinos y pájaros, varaban en la costa en enormes cantidades, donde llegaban "los pobres, y mucha gente de la tierra, y cogen mucho, y lo secan al sol para guardar y para llevar a la sierra".

26 Las Leyes de Indias estipularon que la formación de puertos debía efectuarse en lugares adecuados para el comercio y la defensa, por el peligro latente del ataque de corsarios. En Leyes de Indias, Libro IV, Título VII, De la Población de las ciudades, villas y pueblos. En la ley IIII seńala que no se pueblen puertos, que no sean buenos y necesario; para el comercio y defensa. Un completo estudio sobre la circulación y producción de las minas altoandinas en el período colonial en Salazar, 2009.

27 Archivo General de Indias, Lima 250, No 6. Información: Manuel Rodríguez, 1658. "Información de oficio y parte: Manuel Rodríguez, constructor de obras públicas de la ciudad de Arica, (Iglesia Mayor, fuerte), piloto mayor del Mar del Sur para Valdivia contra los holandeses, alcalde ordinario, natural de Portugal, naturalizado, vecino de San Marcos de Arica”.
Cabe destacar, por último, que los cambios coloniales en las costas no se limitaron a transformaciones de tipo económico y político, pues también envolvieron aspectos culturales y religiosos. Las poblaciones nativas y locales que habitaban los puertos de Iquique y Cobija presenciaron la modificación de su entorno mediante la construcción de templos y la entrega de servicios pastorales. Inicialmente, la evangelización de la población indígena estaba en manos de los encomenderos, quienes debían contratar a un sacerdote y costear los implementos necesarios para el culto (Trelles, 1982, pp. 234-235). En el caso de Iquique, el arrendatario del puerto a inicios del siglo XVII, Juan Donoso, mostró su preocupación por la evangelización de los indios y costeó los elementos necesarios para la entrega de los servicios religiosos, tales como un cáliz de plata, un misal y un manual (Aguilar y Cisternas, 2013). La revisión de los libros parroquiales de la doctrina de Tarapacá permite apreciar que efectivamente la población indígena asentada en la costa recibió al menos el sacramento del bautismo, siendo registrados por el doctrinero bajo la denominación de camanchacas (Larraín y Bugueño, 2011). El relato del John Esquimeling, quien formó parte de la expedición del corsario Sharp que visitó las costas del Iquique a fines del siglo XVII, aporta otras valiosas referencias sobre la evangelización de la población costera. De acuerdo a su relato había "[...] una pequeña isla de veinte o treinta casas, la que posee una pequeña capilla [chapel] próxima, construida de piedra, y como adorno, sobre esta, se encuentra totalmente cubierta de cueros de pieles de focas [seals]" ${ }^{28}$ En las costas de Atacama, el sacerdote y también empresario pesquero Francisco Otal se perfilaba "[...] enseñando e industriando a los indios de este beneficio de atacama la baja y camanchas chiangos auitadores de estos puertos de mar por auer mas de veinte un ańos que aquí les administra Los santos sacramentos y trabajar con ellos enseñándoles en estos dichos puertos como son Cubija Colupo, Yquique y loa y demás partes". ${ }^{29}$ De tal manera que los servicios religiosos de Francisco Otal no se restringieron a los límites de la doctrina de

28 Citado por Larraín y Bugueño, 2011.

29 Archivo General de Indias, Charcas Legajo 92. Probanza de méritos de Francisco de Otal. 1641, f. 23v - 24 r. Documento transcrito y publicado en Castro, 2009. 
Atacama, abarcando puntos neurálgicos de la actividad pesquera y guanera del tenientazgo de Tarapacá. Cabe mencionar que Juan Donoso y Francisco Otal habrían mantenido relaciones comerciales. ${ }^{30}$ No hay que olvidar que las festividades religiosas que restringían el consumo de carnes rojas constituyeron un aliciente para la extracción y consumo de pescados. $^{31}$

Durante los siglos XVI y XVII se vivió entonces los embates del proyecto colonial en la zona costera. Los grupos nativos ribereños fueron subordinados a encomenderos, corregidores y empresarios hispanos y criollos según las demandas del mercado interno colonial. Camanchacas y otras organizaciones sociales originarias vieron reducidos este espacio productivo, así como la imposición de nuevas pautas culturales y religiosas.

\section{Guano y pesca durante el siglo XVIII}

Desde fines del siglo XVII el corregidor empieza a consolidarse como un poder incontenible en sus provincias, teniendo un acceso privilegiado a recursos y mano de obra. En 1708, por ejemplo, el corregidor de Atacama monopolizó el puerto del Loa, lo que le permitió imponer precios arbitrarios al pescado y prohibir su libre comercialización. ${ }^{32}$ Pero aparentemente fue a mediados del siglo XVIII, luego de la legalización de los repartos de mercancías, que los corregidores lograron controlar completamente el comercio de bienes externos y locales, entre ellos y con mayor holgura los marítimos. Existen referencias acerca de cómo los agricultores andinos debieron comprar a elevados precios productos como el guano a sus corregidores. En el caso de Arica, el corregidor Demetrio Egan le habría vendido mediante el reparto forzoso a los caciques de Tacna al

30 Ambos empresarios, Juan Donoso y Francisco Otal, fueron contemporáneos y mantuvieron intercambios económicos. Véase Aguilar y Cisternas, 2013.

31 El obispo de La Plata, por ejemplo, agradeció a Otal en varias oportunidades entre 1641 y 1644 por el regalo de congrios y atún que habían llegado a sus manos frescos y salados, que "es cosa lindísima” (Hidalgo, 2011, p. 121).

32 Archivo y Biblioteca Nacional de Bolivia, Sucre (ABNB) Sección Colonial, diversos. Ec Ad 1708, $\mathrm{N}^{\circ} 10$ precio de 12 reales algunas fanegas de guano que sacaban de la ciudad de Arica y a 2 pesos el guano que extraían de las caletas del Morro y la Quiaca. ${ }^{33}$ Testimonios como el del teniente de capitán y hacendado en Sama Vicente Ortiz Cornejo señalaron que en 1771 Demetrio Egan les hizo repartir en ese valle 100 mulas y 2 mil fanegas de guano. En Ilabaya, el cacique Pheliciano Lupistaca testificó que pagó a Egan 2500 pesos por efectos de Castilla y 1488 por repartos de guano. Al interior de Arica, los principales de Parinacota y Caquena declararon que entre otros efectos el corregidor Egan les repartió 76 fanegas de guano en 114 pesos, mientras que el vecino del valle de Lluta Tomás de Salas mencionó que colaboró en repartos en la doctrina de Codpa de 45 fanegas de guano a 12 reales. ${ }^{34}$

En el siglo XVIII también podemos apreciar el surgimiento de una mayor racionalidad e intencionalidad de las políticas fiscales para garantizar la cobranza de los impuestos y estimular la producción regional. Esto se va a expresar en políticas de "fomento" que requirieron de informes de funcionarios ilustrados, como en el caso del mineral de plata de Huantajaya, así como de ordenanzas de los corregidores para favorecer el comercio y corregir las malas costumbres. Además, se aprecia en este período una mayor frecuencia de las revisitas de tributarios, que junto con hacer un recuento de la población indígena persiguen aumentar los ingresos fiscales (Hidalgo, 1978; Hidalgo, Arévalo, Marsilli y Santoro, 1988; Hidalgo, Castro y González 2004). Esto exigió además que

33 Reparto forzoso de mercancías fue un sistema por medio del cual los corregidores vendían a los indígenas y otros sectores en sus provincias mercaderías que no podían ser rechazadas por los presuntos "compradores". Fue un medio de mejorar significativamente los ingresos de estos altos funcionarios que encarnaban el poder real y a la vez promovían la producción y la circulación mercantil virreinal.

34 Archivo General de Indias, Lima 895. Oficiales Reales v/s Egan. Hay referencia a dueños de barcos que transportan guano. Se agrega que Egan entre 1774 y 1775 repartió en Arica 9.754 fanegas de guano. Otros testimonios dan cuenta de que el teniente de Tarata Francisco Cepeda repartió 7 mil fanegas de guano a precio de doce reales, mientras que Bernardo Téllez de Tacna, dueño de recuas de mulas, pagó por sus peones a quienes Egan les quitaba las aguas si no pagaban. El Alcalde de Toquela, anexo de Tacna, recibió mulas y guano. 
los sacerdotes tuvieran disponibles los libros parroquiales de nacimientos y defunciones para que los visitadores pudieran verificar las informaciones que recibían de los caciques y tributarios. Aun cuando estas fuentes tenían un primer interés eclesiástico, se convirtieron en fuentes complementarias para la demografía y otros aspectos de la vida social de las comunidades andinas. ${ }^{35}$

Por otra parte, durante el siglo XVIII siguió vigente el mecanismo de "licitación" de derechos a puertos, surgidos como hemos mencionado de la "herencia" de derechos de encomienda o mercedes de indios. Existen antecedentes de arriendos a puertos de Loa e Iquique, cuyos "porteros" o arrendatarios poseían el monopolio del guano o de pescado por un período de tiempo. La isla de Iquique aparece como el principal lugar de abastecimiento de guano desde el cual el arrendatario del puerto utilizó indios para la extracción, carga y venta del abono, cuyos compradores eran sujetos de distintas provincias y procedencias, algunas relativamente distantes como Arica, Tarapacá, Atacama e incluso Lipes, también de diversas procedencias sociales, quienes compraban para llevar el guano por tierra a lomo de mulas o por vía marítima. ${ }^{36}$

El siglo XVIII fue una época durante la cual las autoridades virreinales debieron enfrentar de forma cada vez más intensa el contrabando y la competencia por el control marítimo con otras potencias mundiales. La presencia de fragatas extranjeras oca-

35 Para estudios de población del norte de Chile con libros parroquiales, véase Inostroza, 2010; Cisternas, 2012.

36 O’Brien señala que todo el terreno de la isla de Iquique es de huano y "bajan a buscarlo de las Provincias de Arica, Carangas, Lipez, y Atacama, para el cultivo de las tierras, y pagan al arrendatario del Puerto un real por cada costal, cuando a su costa lo conduce a la Playa, y también lo llevan por Mar a varios parages de la costa en donde lo venden quando menos a Diez reales fanega de diez arrobas/... En este Puertto y las Puntas inmediatas se coge con abundancia bariedad de Peses, como son Congrios, Lenguados, Corbinas, Pexesapos, Lizas, Cazon, Sardinas, Cabrillas, Anchevetas, Caballas, Pegerreyes, y otros, no faltando bariedad de mariscos./ del Congrio hazen charquesillo, y lo venden en el mismo Puertto, desde seis asta Ocho pesos, para conducirlo a las Provincias Ynteriores" 'Descripción de Tarapacá, 1765', f. 14r,14v - 15r (Hidalgo, 2009, p. 23). sionará distorsiones en el comercio del guano. En 1725 la fragata francesa Santo Espiritu, recorriendo el sur del Perú, obligó a que las autoridades prohibieran todo comercio en la costa del Pacífico, incluido el del guano. ${ }^{37}$

Las autoridades coloniales buscaron a fines del siglo XVIII normar las actividades productivas costeras tales como la extracción de guano y la pesca. El corregidor de Arica Andrés Ordóñez en 1778 reunió al gremio de barqueros y vendedores de guano, que era el único gremio que subsistía en la ciudad, con el propósito de "la equiedad [equidad] en el govierno de donde dimana que todos Viban de su trabajo sin perjuicios de unos a otros". Se pretendía evitar que algunos individuos con su conducta viciosa aprovecharan ese tráfico solo para ellos. La reunión perseguía lograr acuerdos por unanimidad para regular ese comercio y aplicar multas pecuniarias a quien violara la ordenanza. Se establecía que en los cuatro meses de extracción del guano -que corrían desde septiembre a diciembre- se establecieran turnos de seis días corridos, excluidos los domingos y las fiestas religiosas. El resto del año los turnos serían de ocho días. Los barqueros podrían vender guano solo en sus turnos y serían severamente multados los que no respetaran el acuerdo. Nadie fuera de los firmantes podría participar en este comercio. Se establecía el precio de venta de la fanega de guano en no menos de 8 reales, "que es el que sufraga los costos, dejando una mui corta utilidad". Para establecer el orden de los turnos, cada uno anotó su nombre en un papel que fue depositado en una vasija para que la suerte determinara el resultado. Curiosamente el primer turno o nombre que se registra fue el del propio corregidor Ordóńez, seguido de " $=$ Dn Josef Henriques= Dn Manuel Santan $a=$ Dn Jacinto Blancas $=$ Dn Juan Araujo $/$ Dn Evsevio de Silba $=$ Dn Paulino de Tapia $=$ Dn Demetrio Egan $=$ Dn Josef Lino Portocarrero $="{ }^{38}$

De todos ellos, no aparece al final la firma de Jacinto Blancas, y como apoderado de Demetrio Egan firma Joaquín González Vigil. La presencia del corregidor

37 Archivo Histórico Nacional, Fondo Judicial Administrativo de Arica, Leg. 3 Pieza 7.

38 Archivo Histórico Nacional, Fondo Notarios de Arica, Vol. 37, f. 35r - 36v. Ordenanza de Ordoñez, Arica 1778. 
titular, Andrés Ordóñez, así como la del reciente corregidor Demetrio Egan (1770-1775) muestran la fuerte intervención del poder político en la extracción, transporte marítimo y venta del guano. Las numerosas denuncias contra Egan por abusos en el reparto del guano en los pueblos de los altos de Tacna y Arica indican, además, que este era uno de los productos en el reparto de mercancías o venta forzosa que hacían los corregidores. El resto de los integrantes del gremio eran personas que integraban la élite de hacendados y comerciantes de Arica. Sus intentos de exclusión de otros sectores en este lucrativo negocio demuestran los estrechos lazos entre política y negocios.

Cinco años después, en 1783 , se dictó una reglamentación sobre la conducta que debían seguir los vecinos de Arica. Se prohibía a los revendedores de pescado que alteraran los precios del alimento. ${ }^{39} \mathrm{El}$ reglamento también amenazaba con privar del oficio de pescador a quienes estuvieran durante el día ociosos, sin trabajar. Respecto a la explotación del guano, incorporó la prohibición a los indios de extraer este producto desde el Morro de la ciudad so pena del castigo de azotes, debido al "peligro inminente a que se exponen por haverse experimentado que muchísimos han muerto despeñados". ${ }^{40}$ Es interesante que esta referencia haga alusión a covaderas que normalmente no se encuentran en las descripciones de los cronistas, y que fue un tópico reiterado en las disposiciones de las autoridades de Arica. Puede ser un reflejo de actividades de campesinos que bajaban a la costa a extraer guano en covaderas no controladas por quienes tenían el monopolio de los sitios más ricos de extracción.

39 Archivo Histórico Nacional, Fondo Judicial Administrativo de Arica, Leg. 5 Pieza 3. Reglamentación sobre conducta en la ciudad de Arica 1783. San Pedro de Tacna a 7 días de agosto de 1783 .

40 Archivo Histórico Nacional, Fondo Judicial Administrativo de Arica, Legajo 5, Pieza 3. Reglamentación sobre conducta en la ciudad de Arica 1783. San Pedro de Tacna a 7 días de agosto de 1783 .

\section{Guano y actividades pesqueras entre la crisis colonial y el primer siglo republicano}

La explotación de los recursos marítimos -y el acceso de las comunidades indígenas a estos- se vieron afectados por los cambios políticos y administrativos ocurridos con la desintegración del sistema colonial y la formación de las repúblicas andinas. Durante los primeros años del siglo XIX es posible apreciar la crisis del monopolio comercial hispano, así como los últimos esfuerzos de las autoridades coloniales por proteger y gobernar las costas que bañaban el desierto atacameño. Por otra parte, por aquellos años el guano experimenta una especie de redescubrimiento por parte del mundo europeo, que con el correr de los años impulsará su tráfico intensivo. La disminución de este fertilizante despertará incluso la preocupación de algunas autoridades debido al negativo efecto que se vislumbraba en las actividades agrícolas indígenas regionales. No obstante, como veremos con documentación del siglo XIX, las comunidades se las arreglaron para continuar accediendo a depósitos costeros.

Previo a su definitiva disolución, el sistema colonial promovió una reforma administrativa con miras a recuperar el poder político, mejorar la economía y el control de la sociedad. En 1784, inmediatamente aplastada la gran rebelión andina, la era de los corregidores llegó a su fin, siendo sustituidos por intendentes y subdelegados. Los antiguos corregimientos de Arica y Tarapacá pasaron a formar parte de la Intendencia de Arequipa, mientras que Atacama se erigió como uno de los partidos de la Intendencia de Potosí. ${ }^{41}$ La desaparición de este poderoso funcionario colonial obligó a un proceso de reajuste de los equilibrios políticos locales. Mientras que en otras regiones de los Andes pareciese que caciques y subdelegados heredaron el poder ostentado previamente por los corregidores, en el partido de Arica existen evidencias que nos sugieren que a nivel de doctrina fueron los curas quienes adquirieron un particular protagonismo. Por ejemplo, un cura de la doctrina de Codpa hacia los primeros años del siglo XIX

41 Ver un análisis sobre la introducción del régimen de subdelegados en Arica y Tarapacá en Aguilar, 2013. 
practicaba una especie de reparto de mercancías a los indígenas, incluyendo el guano como uno de los productos (Hidalgo, Díaz y Cisternas, 2014). Entre los testigos indígenas que participaron en un largo proceso judicial seguido contra este sacerdote se encontraba un indígena de la doctrina, quien se hallaba trabajando en las guaneras de la subdelegación. ${ }^{42}$

La Corona española instruyó que los intendentes y subdelegados dieran cuenta de la fiscalidad, bienes y producción de sus provincias (Lynch, 1962; Fisher, 1981), incluyendo la revisión de las posesiones reales como puertos, islas y litorales. Fiel a las ordenanzas, el intendente de Arequipa Antonio Álvarez y Jiménez llevó a cabo una indagación de las islas guaneras de sus costas con el fin de determinar si existían usufructuarios, ya sea comunidades o particulares, y si acaso gozaban de la debida legitimidad (Barriga, 1941, p. 26). Su pesquisa arrojó que mientras las actividades pesqueras "[...] eran francas en las Costas de estos mares" (Barriga, 1941, p. 86) no sucedía lo mismo con la explotación de las islas guaneras por lo que se debían cobrar derechos. El intendente registró la existencia de barcos guaneros que extraían el abono para vender a los labradores con el fin de "[...] animar, fomentar y cultivar sus tierras” (Barriga, 1941, p. 86).

Intendentes y subdelegados debían igualmente proteger los mares y sus recursos de las potencias extranjeras, cuyos barcos solían asediar los puertos virreinales. Evidencias documentales de este período demuestran que las autoridades estuvieron especialmente preocupadas por la intromisión de barcos realizando caza de ballenas. ${ }^{43} \mathrm{El}$ intendente de Po-

42 Archivo Arzobispal de Arequipa, Legajo Arica, Codpa, Años: 1650-1891, Expediente 4 enero de 1804. Denuncia en contra del cura Delgado de Codpa. Este documento parece ser una copia incompleta del que se encuentra en: Ministerio RREE del Perú: Departamento de Archivo de límites, No ARV -7; Leg. 415; Año: 1804; 111 fs. Útiles, 7ff en blanco. Doc. Cuaderno de la Santa Visita a la Doctrina de San Martín de Codpa.

43 De acuerdo a Flores (2011) las pieles de nutria y foca, $y$ en especial el aceite de ballena, alcanzaron en este período un alto precio en los mercados de Europa y Oriente, situación que incentivó la navegación en aguas territoriales españolas del Pacífico por parte de embarcaciones extranjeras, abriendo el debate sobre la apertura comercial y los derechos exclusivos de navegación en tosí propuso la creación de un establecimiento para la caza de ballenas en el puerto de Cobija, perteneciente al partido de Atacama. ${ }^{44}$ A su modo de ver en el control de los mares se enfrentaba a dos visiones jurídico-políticas. Por una parte, el derecho de gentes que según algunas potencias implicaba que el mar y la pesca eran indivisibles, no admitiéndose los límites convencionales debido a la inmensidad del océano. De acuerdo a esta visión, se legitimaba la introducción de embarcaciones inglesas cazando ballenas por el Mar del Sur como había ocurrido en Arica, Pisco y Atacama hacia 1789. Por otra parte se hallaba el derecho público que defendía el señorío de los soberanos sobre tierras y mares. ${ }^{45}$ No obstante la propuesta y reflexión de este intendente, barcos extranjeros dedicados a la caza de ballenas siguieron surcando las costas del sur peruano. ${ }^{46}$ Algunos intendentes, como el mencionado Antonio Álvarez y Jiménez, idearon proyectos para fortalecer los puertos, pero las capacidades defensivas se mantuvieron débiles a lo largo de este período.

Embarcaciones no hispanas no solo fueron acusadas de contrabando y de la caza de ballenas, sino que

el Mar del Sur.

44 Descripción del Puerto de Cobija elaborado por Pedro Vicente Cañete y Domínguez, 1787. Transcrito y publicado en Revista Norte Grande, 1(1), 1974.

45 Esta última visión que defendía el Intendente de Potosí pone de relieve el amparo ideológico que movía a las autoridades de la época, una especie de rescate de la ideología señorial/imperial hispana: “...el señor del territorio también lo debe ser de los mares adyacentes, para el amparo, conservación y defensa de los usos del dominio, y es por estos es intitularse los Monarcas de España Reyes de las Indias Occidentales, Islas y Tierra firme del Mar Océano, con un derecho más justificado, que aquel que se arrogó el pueblo romano”. Ver Pedro Vicente Cañete y Domínguez. Descripción del Puerto de Cobija, 1974 [1787], pp. 83-84. Transcrito y publicado en Revista Norte Grande, 1(1), 1974. Sobre la construcción ideológica del señorío universal, consúltese Pagden, A., 1997.

46 En 1792, el Intendente de Arequipa informó al Subdelegado de Arica de la presencia de algunos individuos que se separaron de la fragata Lucia, procedente de Dunquerque y con bandera francesa, cuya presencia en estas costas obedecía "a la pesca de ballena”, por lo que se solicitó estar atento a su captura y remitirlos a la capital del virreinato. Archivo Histórico Nacional, Fondo Administrativo de Arica, Legajo 8, Pieza 71. 18 de enero de 1792 . 
también de la recolección de guano. En su memoria de gobierno, el intendente de Arequipa, Bartolomé María de Salamanca (1796-1811) denunció que sin su consentimiento barcos extranjeros extraían guano para su envío a tierras europeas. ${ }^{47}$ Se evidencia aquí un cambio en el destino del guano explotado desde las costas de Iquique y Arica. Mientras durante la temprana época colonial el guano fue orientado principalmente al mercado interno andino, en esta coyuntura se observa su decidida apertura al mercado internacional, un presagio de lo que será finalmente su trayectoria decimonónica.

Las actividades extranjeras de extracción de guano no se pueden disociar del interés ilustrado y europeo por el estudio de este fertilizante y otros recursos naturales americanos, que fueron difundidos en obras y autores de fines del siglo XVIII y comienzo del XIX. ${ }^{48}$ Particular importancia en este sentido parece tener Alexander von Humboldt, quien tras su visita al Perú realizó gestiones para averiguar las propiedades y beneficios del guano, fomentando así su posterior utilización masiva en el mercado europeo (O’Phelan, 2010). Humboldt envió en 1802 remesas de guano para su análisis químico en Francia, confirmando su alto contenido de nitrógeno y fosfato, lo que lo convertía en un fertilizante superior a los utilizados por ese entonces. ${ }^{49}$ Además de rescatar

47 Fisher, 1968. Sobre el gobierno de Bartolomé María Salamanca, consúltese también O'Phelan, 2012.

48 No es nuestro propósito aquí componer una genealogía de estos viajes y obras. Podríamos mencionar textos como los de Pedro Ureta y Peralta, Cosme Bueno, y la Geografía del Perú de 1814. Esta última fue realizada a instancia de la Regencia de Cádiz que promovió una recopilación de descripciones geográficas de los territorios ultramarinos de la Monarquía, y siguiendo a Cosme Bueno respecto a Iquique señaló que estaba “.... dos leguas de Huantajaya, en que hay pesquerías de tollo, que es el bacalao de esta América, y de congrio que se lleva a las provincias de la sierra”. Castillo et al. (1994 [1814], pp. 422-423). En el siglo XIX, autores peruanos y británicos continuarán con esta tradición ilustrada de estudiar los beneficios del guano. Una investigación actual sobre el impacto de la apertura comercial del guano y el impacto en las ecologías véase en Cushman, 2013.

49 Cabe agregar que autores peruanos y británicos continuarán con esta tradición ilustrada de estudiar el origen y usos de los beneficios del guano del Perú. Por ejemplo, en 1827, en los inicios de la república peruana, Mariano Eduardo de Rivero publicó Memoria sobre el Guano de sus atributos químicos, Humboldt dejó evidencias en sus memorias del valor que le atribuían las poblaciones locales, consignando su preocupación por la conservación del recurso. ${ }^{50}$

No cabe duda de que los depósitos de guano a inicios del siglo XIX fueron decisivos en la economía del puerto de Arica. Además de atraer embarcaciones extranjeras, el guano impulsó el comercio, la agricultura y una inédita industria naviera. En 1804, el alcalde de Arica dejó un extraordinario testimonio de lo anterior en una comunicación dirigida al intendente de Arequipa Bartolomé María de Salamanca. El comercio del guano de pájaro era uno de los ramos más relevantes en el puerto de Arica realizado por los vecinos de la ciudad, quienes poseían barcos y que anualmente introducían 15 a 16 mil fanegas de este estiércol para abonar las tierras. La agricultura de la provincia era absolutamente dependiente del guano según el alcalde, quien estimaba que sin el fertilizante las tierras no producirían ni la cuarta parte de sus frutos. El comercio de guano también favorecía la fiscalidad tardía colonial, derivada de los cobros de almojarifazgo y alcabala. Además el negocio del guano impulsaba el desarrollo de infraestructura naviera en Arica.

Por lo que respecta a favricas en este Distrito, no hay otras que la construcsion, de algunas embarcasiones que se favrican/ en este Puerto, para conservar el comercio de Huano; y estas pequeñas siendo las mayores; de tres a quatro mil quintales de cargas. Para la construcion de estas, se valen los vesinos de esta dicha ciudad de maderas, de los olivos, para las ligasones, quillas y

Pájaros y su uso en el Perú, Lima, Imprenta de la Instrucción Primaria. En ella sostenía que los incas habían explotado el guano, y que además existían evidencias de antiguos instrumentos cortantes indígenas en los roqueríos e islas sur peruanas, lo que daba cuenta de su uso por parte de poblaciones originarias. Mariano Eduardo de Rivero había sido discípulo de Humboldt en Francia. Véase Contreras y Zuloaga, 2014.

50 Humboldt destacó que los incas prohibieron la caza de las aves instaladas en las islas de guano para que continuarán reproduciéndose, constando en este hecho la importancia que tenía el guano para la producción agrícola del Perú. Núñez y Petersen, 2002. 
sobrequillas, y Gurveria; por lo que hase a tavlason, y arboladura solicitan conseguirla de Guayaquil.: la dicha tavlason de madera de roble, y la arboladura de Lauren, o Maria; pues por estos parages, no produsen estos dos presisos renglones. ${ }^{51}$

Podemos apreciar que el comercio del guano en los albores del siglo XIX obligó a quienes se lo habían apropiado a crear una industria compleja que incluía su extracción y transporte, así como la construcción de embarcaciones que implicaba uso de maderas producidas localmente como el olivo y otras que venían de Guayaquil. Tal "fábrica" seguramente exigía la presencia de carpinteros y diseñadores. Es probable que este astillero fuese más antiguo, pues con anterioridad el intendente Antonio Álvarez y Jiménez, en su visita a Arica de 1793, informó que la ciudad "[n] o tiene maderas útiles para la construcción de bageles ni exquistas para comerciar con ellas, bien que para cortos buques ha solido servir, desde los ligamentos, costillages y cubería, la de sus famosos olivos que es muy a propósito e incorruptible en el agua". ${ }^{52}$

Comunidades indígenas y autoridades regionales se preocuparon por los altos niveles de explotación del guano a fines del siglo XVIII, y alarmaron a las autoridades sobre los riesgos para la vida agrícola regional e indígena, en caso de que el recurso escaseara. Así se lo hicieron saber tanto el subdelegado de Tarapacá como las comunidades de Sibaya, Camiña y también el común de indios y vecinos hispanos de Pica al intendente Bartolomé María de Salamanca en 1798. El intendente era consciente de estos posibles daños para el cultivo y fomento de la tierra. Sabía, por ejemplo, que importantes depósitos de guano como los acumulados en la isla de Iquique se hallaban ya en aquel entonces prácticamente extinguidos, a causa de su sistemática extracción. Además, tenía conocimiento de que el guano de Iquique no podía renovarse debido a que muchos vecinos iban a marisquear y raspar el poco producto que quedaba, espantando de este modo a las aves marinas, por lo que había encomendado la prohibición

51 Archivo Histórico Nacional, Fondo Notarial de Arica, Vol. 4.

52 Barriga, 1948, T. III, p. 67. de cualquier tipo de extracción en el lugar. ${ }^{53}$ Por esta razón, el intendente mandó publicar un inédito bando en todos los puertos, caletas y embarcaderos de las subdelegaciones de Tarapacá, Arica y Camaná prohibiendo bajo severas sanciones la extracción de guano desde la isleta de Guasilobo hasta Patillo y Guano Grande, protegiendo estas zonas de extracción para la agricultura del partido de Tarapacá. ${ }^{54}$ Con esta medida, el intendente negaba la libertad de extracción del guano creando una reserva para los indígenas y vecinos de los pueblos tarapaqueños, intentando no repetir lo ocurrido en Iquique. Los barcos seguirían teniendo permiso para la extracción al norte de estos puntos.

En las postrimerías de la era colonial se vivieron otras importantes transformaciones durante el funcionamiento de las Cortes de Cádiz. En plena crisis de la monarquía borbónica, esta corte dio a luz la Constitución de 1812 que -entre otras disposiciones- abolió los derechos seńoriales y de encomienda a lo largo de los dominios ultramarinos de la Monarquía. Esto marcaba el ocaso del sistema de arrendamiento de puertos que había funcionado a lo largo del período colonial para organizar la explotación marítima y la obtención de guano en las costas del desierto de Atacama (Villalobos, 1979).

La Guerra de Independencia tuvo efectos en las economías campesinas andinas. Muchos bienes de las comunidades fueron confiscados para financiar las distintas tropas -monárquicas o patriotas- que recorrieron el desierto. Otro efecto habría sido el aumento de los precios de productos estratégicos como el guano, lo que sin duda afectó seriamente la economía campesina durante aquel conflicto.

53 Archivo Histórico Nacional, Fondo Judicial Administrativo de Arica, Legajo 9, Pieza 17. Mariano Rivero (1827) acreditó esta información señalando que "El primer guano procedía de la isla de Iquique, motivo por el cual este producto importante lleva en todo el Perú el nombre de esta isla, que dista unos 325 metros del puerto de Iquique. La pequeña isla tiene aproximadamente 670 metros de largo y 170 metros de ancho. Actualmente las canteras de guano están agotadas". Véase Núñez y Petersen, 2002.

54 Archivo Histórico Nacional, Fondo Judicial Administrativo de Arica, Legajo 9, Pieza 17. 
El temprano Estado republicano peruano, al igual que los últimos gobernantes borbones, se preocupó de la presencia de embarcaciones extranjeras que pescaran, cazaran o comercializaran productos marinos en el territorio. Ante ello, las autoridades intentaron implementar una normativa que privilegiara el acceso a los recursos marítimos por parte de la población local o nacional. En 1822 se despachó un decreto que exigía a todas las personas que desearan pescar en puertos y caletas el registro de matrículas ante los capitanes de puerto o subdelegados de Marina. Estas normativas aplicaban a los pescadores que disponían de buques, y solamente implicaba un gravamen en el caso de que la embarcación tuviera un arqueo superior a las 20 toneladas. ${ }^{55}$ En 1833, el Estado republicano peruano prohibió que barcos extranjeros pescaran en playas e islas peruanas, propiciando así que la pesca de cetáceos, anfibios y otras especies quedarán especialmente reservada para los ciudadanos peruanos. ${ }^{56}$

Durante la primera mitad del siglo XIX, el Estado republicano peruano vivió los beneficios fiscales del boom de la exportación del guano, lo que le permitió entre otras políticas prescindir de los tributos indígenas hacia $1854 . .^{57} \mathrm{La}$ minería del guano en las covaderas de Tarapacá después de la Guerra del Pacifico habría generado condiciones para la temprana aparición de un peonaje guanero con capacidad de organización y acción de protesta social (Pinto, 1990). Si bien grandes cantidades de guano habrían de ser destinadas al mercado internacional, las poblaciones locales de todas maneras continua-

55 Archivo Digital de la Legislación del Perú, Decreto 18 de marzo, 1822.

56 Archivo Digital de la Legislación del Perú, Decreto 6 de septiembre, 1833. Véase también al respecto ADLP, Decreto 5 de agosto, 1833 de Agustín Gamarra sobre los capitanes de puerto. En esta temprana legislación republicana sobre asuntos marítimos se consideraba que las embarcaciones extranjeras eran invasoras de la propiedad, cuya actividad afectaba el empleo de los naturales del país.

57 De acuerdo a Gracia Fadrique et al. (1988), Perú fue la mayor reserva mundial de guano. Durante la primera mitad del siglo XIX, países como Inglaterra en 1820 y otras potencias emergentes como Estados Unidos en 1832 desarrollarán un comercio relativamente estable de este fertilizante, si bien el auge de la exportación ocurrió después de 1843. rán teniendo acceso al fertilizante. ${ }^{58}$ Comunidades y poblaciones rurales de Tarapacá seguirán obteniendo este abono, ya sea por medio de su compra a subastadores u otros agricultores, ya sea directamente extrayéndolo desde depósitos costeros. En 1827, Mariano Eduardo de Rivero señalaba que los “... huatacondes y quillaguas conocen también el guano en un punto que está situado a unos 40 kilómetros de la Punta de Lobos" (Rivero, 1827). Finalizada la Guerra del Pacífico (1879-1883), hay evidencias de que arrieros de Huatacondo frecuentaban Guanillos donde intercambiaban guano por leña y carbón (Zolezzi, 1993). En 1880, el jefe político de Tarapacá permitió por medio de un decreto el traslado de guano por tierra, exento de impuesto, para el beneficio de los cultivos de Pica y Huatacondo. ${ }^{59}$ No sabemos hasta qué punto esta decisión pudo responder a un tráfico de guano para estas poblaciones, que estuvo amparada por la reserva de depósitos promovida por el intendente Bartolomé María de Salamanca al finalizar el gobierno colonial. Sea como fuere, autoridades chilenas encargadas del litoral sur de Tarapacá dieron cuenta en los primeros años de administración chilena de que pequeñas embarcaciones, descritas como "canoas de pescadores", navegaban por Patillo y Patache y pequeños islotes extrayendo el guano de pájaro, el que luego era llevado a lomo de mula hacia estos valles. ${ }^{60}$ En 1885 , el permiso del jefe político de 1880 seguía vigente, al punto que el subprefecto de Patillo informó que tres veces al mes una tropa de 25 mulas llegaba a cargar guano en las covaderas de la punta Patache, existiendo "[...] un permiso que está bijente en que se permite estraer esta sustancia a los del interior para el abono de sus tierras". ${ }^{61}$

58 Un reglamento que disponemos para Arica de 1878 hace referencia a los costos y mecanismos de compraventa de toneladas de guano por parte de los agricultores. AHN, Fondo Intendencia de Tacna, Reglamento para la venta del guano en los depósitos del Departamento modificado aprobado por la Prefectura en vista del proyecto presentado por el subastador de dicho abono.

59 Archivo Histórico Nacional, Fondo Intendencia de Tarapacá, Volumen 91.

60 Ibíd.

61 Archivo Histórico Nacional, Fondo Intendencia de Tarapacá, Volumen 91, s/f original: El subprefecto luego descubrió que era Epifanio Nuñez "que tiene la contrata de surtir de pólvora a las guaneras de Pabellón de Pica, es el que con su tropa de regreso la carga con guano, 


\section{Conclusiones}

La potencialidad del guano en las actividades agrícolas, ya conocida en tiempos prehispánicos, generó profundas transformaciones, no solo en la agricultura, sino también en las organizaciones políticas tanto de altura como en aquellas de la costa, que buscaron acceder al recurso en términos armónicos, reciprocitarios y de beneficio mutuo. Como señala Horta (2015), ha sido el guano obtenido por los camanchacas de Arica, gracias a su habilidad como navegantes y pescadores oceánicos, el producto que pudieron ofrecer a los grupos de agricultores de tierras bajas y altas, recibiendo en intercambio recíproco otros bienes como tejidos, alimentos y materias primas.

La llegada de los conquistadores rompió estos circuitos y alianzas, a lo que se agregó la apropiación en la costa de Arica y Tarapacá de las más ricas covaderas por parte de vecinos y autoridades españolas que procuraron controlar el comercio del guano y la pesca. Los camanchacas fueron obligados a un continuo empobrecimiento y pérdida de poder de negociación. Se transformaron en mano de obra marítima para los encomenderos y vecinos. Los europeos y los criollos procuraron establecer nuevas formas de control de los recursos y aplicar sus tecnologías a la nueva industria, como la construcción de barcos y normas que limitaban el acceso y el comercio en beneficio del grupo de poder dominante.

No se puede separar este florecimiento de la explotación del guano colonial del auge del comercio colonial, y su reestructuración con la explotación de los minerales de la Audiencia de Charcas. El crecimiento del mercado interno colonial seguramente es incomprensible sin los recursos que llegaban desde los distintos puertos del Pacífico, que eran además los puntos de contacto con el resto del mundo. La instalación de puertos, sin duda alteró el paisaje de la costa y limitó el acceso de las sociedades indígenas a los recursos provenientes de la costa.

Desde finales del siglo XVIII, la intensificación de la extracción del guano pareciese tener dos caras. Por

cuyo depósito lo tiene establecido a el pueblo de Pica con el objeto de espenderlo a quien lo necesite". un lado, el ramo del guano promueve las interacciones regionales, la agricultura local y el desarrollo naviero. Por otro lado, comunidades indígenas y autoridades advertirán los riesgos de su sobreexplotación, como queda demostrado por la extinción de los depósitos de Iquique, aquel extraordinario depósito que los cronistas no dudaron en calificar como otra "mina”. Para ello se tratará de crear un área de reserva de guano para la agricultura del partido de Tarapacá, y en apoyo a los campesinos andinos. La época republicana se caracteriza por la inserción del fertilizante en los mercados internacionales, queriendo de esta forma aprovechar esta riqueza acumulada en la costa por milenios.

Sin perjuicio del despojo y las limitaciones para acceder a la riqueza marina, luego de su apropiación por parte de sectores hispanos, criollos y extranjeros a lo largo de la época colonial y republicana, los campesinos andinos parecen hallar las formas de contraponerse a esa desafección participando en las reglas del mercado, pero también obteniendo el fertilizante de manera directa en los depósitos litorales, asegurando de esta forma buenos sembríos para el sostén familiar y comunitario.

\section{Agradecimientos}

Este artículo forma parte del Proyecto FONDECYT 1130667 Historia de los pueblos andinos de Arica, Tarapacá y Atacama: dinámicas imperiales, agencias indígenas y redes andinas de sociabilidad colonial.

\section{Referencias citadas}

Aguilar, J. (2013). Politicas Imperiales, Subdelegados y Sociedades Indigenas. Los partidos de Arica y Tarapacá entre el tributo y la civilización. 1784-1824. Tesis de Magíster en Historia, mención Etnohistoria. Universidad de Chile, Santiago.

Aguilar, J. y Cisternas, P. (2013). Pesquerías coloniales en Tarapacá, siglo XVII. Mercado interno y cristianización. Allpanchis, 81/82, 155-196.

Aldunate, C., Castro, V. y Varela, V. (2010). Los atacama y el pescado de Cobija en Homenaje al Maestro John Murra. Chungara. Revista de Antropología Chilena, 42(1), 341-347. 
Álvarez, L. (2014). Etnopercepción andina: valles dulces y valles salados en la vertiente occidental de los Andes. Diálogo Andino, 44, 5-14.

Assadourian, C. (1979). La producción de la mercancía dinero en la formación del mercado interno colonial. En Florescano, E. (Comp.). Ensayos sobre el desarrollo económico de México y América Latina 1500-1975 (pp. 223292). México: Fondo de Cultura Económica.

Assadourian, C. (1982). El sistema de la economía colonial. Mercado interno, regiones y espacio económico. Perú: Instituto de Estudios Peruanos.

Bakewell, P. (1989). Mineros de la Montaña Roja. El trabajo de los indios en Potosí, 1545-1650. Madrid: Alianza.

Barriga, V. (1941). Memorias para la Historia de Arequipa. Relaciones de la Visita al Partido de Arequipa por el Gobernador $\square$ Intendente Don Antonio Álvarez y Jiménez. Tomo I, 1786-1791. Arequipa: Editorial La Colmena, S.A.

Barriga, V. (1946). Memorias para la Historia de Arequipa. Relaciones de la Visita al Partido de Arequipa por el Gober-

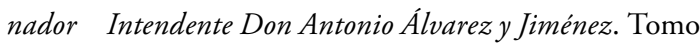
II 1790-1793. Arequipa: Editorial La Colmena, S.A.

Barriga, V. (1948). Memorias para la Historia de Arequipa. Relaciones de la Visita al Partido de Arequipa por el Gober-

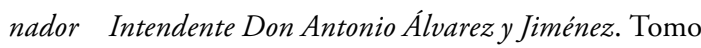
III 1763-1796. Arequipa: Editorial La Colmena, S.A.

Bird, J. (1946). The Cultural Sequence of the North Chilean Cost. In Steward, J. (Ed.). Handbook of South American Indias, Bulletin 143, vol. II The Andean Civilization (pp. 587-594). Washington D.C.: Smithsonian Institution.

Bittman, B. (1986). Recursos naturales renovables de la costa del norte de Chile: modos de obtención y de uso. En Masuda, S. (Ed.). Etnografia e historia del mundo andino: continuidad y cambio (pp. 269-334). Tokio: Universidad de Tokio.

Castillo, F., Figallo, L. y Serrera, R. (1994 [1814]). La Geografía del Perú de 1814 y las Cortes de Cádiz y la última geografía del Perú colonial. En Las Cortes de Cádiz y la imagen de América (La visión etnográfica y geográfica del Nuevo Mundo) (pp. 397-504). Cádiz: Universidad de Cádiz.
Castro, V. (2009). De Ídolos a Santos. Evangelización y Religión Andina en los Andes del Sur. Santiago, Chile: Fondo de Publicaciones Americanistas Universidad de Chile Centro de Investigaciones Diego Barros Arana. Colección Antropología, Dirección de Bibliotecas, Archivos y Museos (DIBAM).

Choque, C. y Muñoz, I. (2016). El Camino Real de la Plata. Circulación de mercancías e interacciones culturales en los valles y Altos de Arica (siglos XVI al XVIII). Historia, 49(1), 57-86.

Cieza de León, P. (1986 [1553]). Crónica del Perú. Primera Parte. Introducción de Franklin Pease G. Y. Nota de Maticorena E, M. Segunda edición corregida. Lima: Pontificia Universidad Católica del Perú, Academia Nacional de la Historia.

Cieza de León, P. (1986 [1553]). Crónica del Perú. Segunda Parte. Edición, prólogo y notas de Cantú, F. Segunda edición corregida. Lima: Pontificia Universidad Católica del Perú, Academia Nacional de la Historia.

Cisternas, P. (2012). El Corregimiento de Atacama en visperas de las transformaciones borbónicas. Configuraciones coloniales y dinámicas demográficas, s. XVIII. Tesis de Magíster en Historia, con mención en Etnohistoria, Universidad de Chile, Santiago.

Contreras, C. y M. Zuloaga. (2014). Historia Minima del Perú. México: El Colegio de México.

Cook, N. (1975). Tasa de la visita general de Francisco de Toledo. Lima: Universidad Mayor de San Marcos.

Cook, N. (1981). Demographic Collapse: Indian Peru, 1520 1620. Cambridge: Cambridge University Press.

Cook, N. (2010). La catástrofe demográfica andina. Perú 1520-1620. Lima: Fondo Editorial Pontificia Universidad Católica del Perú.

Craig, A. (1982). Ambiente costero del norte de Chile. Chungara, 9, 4-20.

Cúneo-Vidal, R. (1977). Historia de la Fundación de la ciudad de San Marcos de Arica. En Obras Completas. Tomo 5, vol. IX. Prado, I. (Ed.) (pp.7-213). Lima: Gráfica Morsom. 
Cushman, G. (2013). Guano and the opening of the Pacific World. A global ecological history. New York: Cambridge University Press.

Dagnino, V. (1909). El Correjimiento de Arica 1535-1784. Arica: Imprenta La Época.

Escobari, L. (1985). Producción y comercio en el espacio sur andino s. XVII. La Paz: Embajada de Espańa.

Falabella, F., Uribe, M., Sanhueza, L., Aldunate, C. e Hidalgo, J. (Eds.) (2016). Prehistoria de Chile: desde sus primeros habitantes hasta los Incas. Santiago: Editorial Universitaria.

Fisher, J. (1968). Arequipa 1796-1811. La relación del gobierno del Intendente Salamanca. Lima: Universidad Mayor de San Marcos, Seminario de Historia rural andina.

Fisher, J. (1981). Gobierno y sociedad en el Perú colonial. El régimen de las intendencias 1784-1814. Lima: Fondo Editorial Pontifica Universidad Católica del Perú.

Flores, R. (2011). Los balleneros anglo-estadounidenses y la cuestión de la "extranjerización" del comercio peruano a fines de la época colonial, 1790-1820. América Latina en la Historia Económica, 36 (jul.-dic.), 39-64.

Glave, L. (1989). Trajinantes. Caminos indigenas en la sociedad colonial, siglos XVI-XVII. Lima: Instituto de Apoyo Agrario.

Gracia Fadrique, J. (Coord.) (1988). Estados y Fertilizantes 1760-1985. (Colección La Industria Paraestatal en México, 8). México: FCE, Semip, Fertimex, UNAM.

Hidalgo, J. (1978). Revisita a los Altos de Arica en 1750. Arica: Departamento de Antropología, Universidad del Norte.

Hidalgo, J. (1981). Fechas coloniales de fundación de Toconao y urbanización de San Pedro de Atacama. Chungara, $18,255-264$.

Hidalgo, J. (1996). Relaciones protohistóricas entre las poblaciones locales y altiplánicas en Arica. En Albó, X., Arriata, M., Hidalgo, J., Núñez, L., Llagostera, A., Remy, M. y Revesz, B. (Comps.). La integración Surandina, cinco siglos después (pp. 161-173). Cusco: Centro de Estudios Regionales Andinos Bartolomé de Las Casas y Universidad Católica del Norte.
Hidalgo, J. (2009). Civilización y fomento: La "Descripción de Tarapacá” de Antonio O’Brien, 1765. Chungara. Revista de Antropología Chilena, 41(1), 5-44.

Hidalgo, J. (2011). Redes eclesiásticas, procesos de extirpación de idolatrías y cultos andinos coloniales en Atacama, siglos XVI y XVII. Estudios Atacameños. Arqueología y Antropología Surandinas, 42, 113-152.

Hidalgo, J. (2014a). Atacama colonial. De la conquista a la colonia. En Atacama (pp. 110-156). Santiago: Ediciones Museo Chileno de Arte Precolombino.

Hidalgo, J. (Ed.) (2014b). Historia Andina en Chile II: Politicas imperiales, dinámicas regionales y sociedades indigenas. Santiago: Editorial Universitaria.

Hidalgo, J. (2014c [2011]). Damián de Morales de funcionario colonial a primer colonizador hispano en Pica: Un actor y testigo del sur andino en la primera mitad del siglo XVIII. En Hidalgo, J. (Ed.). Historia Andina en Chile Vol. II: Politicas imperiales, dinámicas regionales y sociedades indigenas (pp.83-108). Santiago: Editorial Universitaria.

Hidalgo, J. y Focacci, G. (1986). Multietnicidad en Arica, siglo XVI, evidencias etnohistóricas y arqueológicas. Chungara, 16/17, 137-147.

Hidalgo, J., Arévalo, P., Marsilli, M. y Santoro, C. (1988). Patrón de la Doctrina de Belén en 1813: Un Caso de Complementariedad Tardia. Arica: Documento de Trabajo No 4, Facultad de Estudios Andinos, Universidad de Tarapacá.

Hidalgo, J., Schiappacasse, V., Niemeyer, H., Aldunate, C. y Solimano, I. (Eds.) (1989). Culturas de Chile Prehistoria. Desde sus origenes hasta los albores de la conquista. Santiago: Editorial Andrés Bello.

Hidalgo, J. (1993). Algunas notas para la historia del olivo en Arica. IDESIA, 12, 31-50.

Hidalgo, J. (2004 [2003]). Pescadores del litoral árido de valles y quebradas del norte de Chile y su relación con agricultores, siglos XVI y XVII. En Hidalgo, J. (Ed.). Historia Andina en Chile (pp. 431-470). Santiago: Editorial Universitaria. 
Hidalgo, J., Castro, N. y González, S. (2004). La revisita de Codpa del corregidor Demetrio Egan, 1772. Chungara. Revista de Antropología Chilena, 36(1), 95-198.

Hidalgo, J., Díaz, V. y Cisternas, P. (2014 [1985]). Cartas del obispo de Arequipa sobre los indios del corregimiento de Arica, 1620-1638. Cuatro documentos inéditos. En Hidalgo, J. (Ed.). Historia Andina en Chile Vol. II: Politicas Imperiales, Dinámicas Regionales y Sociedades Indigenas (pp. 159-170). Santiago: Editorial Universitaria.

Hidalgo, J., Aguilar, J. y Castro, N. (2014). “Después del Corregidor. Reformulación del poder colonial en los Altos de Arica a inicios del siglo XIX”. Ponencia presentada en IX Congreso Internacional de Etnohistoria, Universidad de Tarapacá, Arica, 10-14 de noviembre. Ms.

Henríquez, F. (2003). Productos y organización técnica del trabajo en Azapa durante el siglo XVIII: poniendo chacra de ají, cogiendo aceitunas. Chungara. Revista de Antropología Chilena, 35(1), 125-140.

Horta, H. (2015). El Señorío Arica y los Reinos Altiplánicos (1000-1540 d.C.) Complementariedad ecológica y multietnicidad durante los siglos pre-conquista en el norte de Chile. Chile: Quillqa, Universidad Católica del Norte.

Inostroza, X. (2010). Sociedad indigena en su interrelación con la sociedad colonial en la Provincia de Arica, segunda mitad del siglo XVIII. Tesis de Magíster en Historia, mención Etnohistoria. Universidad de Chile, Santiago.

Jiménez de la Espada, M. (1965). Relaciones Geográficas de Indias. Tomo I. Madrid: Atlas.

Julien, C. (1985). Guano and Resource Control in Sixteenth-Century Arequipa. In Masuda, S., I. Shimada, I and Morris, C. (Eds.). Andean Ecology and Civilization. An Interdisciplinary Perspective on Andean Ecological Complementarity (pp. 185-231). Tokyo: University of Tokyo Press.

Larraín, H. (1974). Demografía y asentamiento de los pescadores costeros del sur peruano y norte chileno según informes del cronista Antonio Vázquez de Espinosa (1617-1618). Revista Norte Grande, I, 55-80

Larraín, H. (1978). Análisis demográfico de las comunidades de pescadores changos del Norte de Chile en el siglo XVI. Thesis Master of Arts in Department of Anthropology
State University of New York at Stony Brook.

Larraín, H. y Bugueño, V. (2011). Presencia de un ayllu de camanchacas en el puerto de Iquique en el siglo XVII. Revista de Geografía Norte Grande, 50, 7-21.

Larson, B. (1988). Transformation in Bolivia: Cochabama, 1550-1900. Princeton: Princeton University Press.

Lizárraga, R. (1987 [1603-9]). Descripción del Perú, Tucumán, Río de La Plata y Chile. Ballesteros, I. (Ed.). Madrid: Historia 16.

Llagostera, A. (1976). Hipótesis sobre la expansión incaica en la vertiente occidental de los Andes Meridionales. En Casassas, J.M. (Ed.). Homenaje al R.P. Gustavo Le Paige S.J. (pp. 203-218). Antofagasta: Universidad del Norte.

Llagostera, A. (1979). Tres dimensiones en la conquista prehistórica del mar. Un aporte para el estudio de las formaciones pescadoras de la costa sur andina. En Actas del VIII Congreso de Arqueología Chilena (pp. 217-245). Valdivia, Chile.

Llagostera, A. (1989). Caza y pesca marítima (9.000 a 1.000 a.C.). En Hidalgo, J., Schiappacasse, V., Niemeyer, H., Aldunate, C., e Solimano, I. (Eds.). Culturas de Chile. Prehistoria desde sus origenes hasta los albores de la Conquista (pp. 57-79). Santiago: Editorial Andrés Bello.

Llagostera, A. (1993). La navegación prehispánica en el norte de Chile: bioindicadores e inferencias teóricas. Chungara. Revista de Antropología Chilena, 24-25, 37-51.

Lockhart, J. y Schwartz, S. (1992). América Latina en la edad moderna. Una historia de la América española y el Brasil coloniales. España: AKAL Ediciones.

Lohmann Villena, G. (2001). El Corregidor de indios en el Perú bajo los Austrias. Lima: Fondo Editorial Pontificia Universidad Católica del Perú.

Lynch, J. (1962). Administración colonial española: el sistema de Intendencias en el virreinato del Río de la Plata. Buenos Aires: Editorial Universitaria de Buenos Aires.

Martínez, J., Sanhueza, C., Odone, C. y Ruiz, A. (1992). Transcripción Probanza de méritos y servicios de Francisco Altamirano y su padre, Juan Velázquez Altamirano. AGI Charcas, Legajo 80, 133 fs. (año 1596). Estudios Atacameños, 10, 35-75. 
Medinacelli, X. (2010). Sariri. Los llameros y la construcción de la sociedad colonial. La Paz: ASDI, Instituto Francés de Estudios Andinos, Plural Editores, Instituto de Estudios Bolivianos.

Murra, J. (1964). Una apreciación etnológica de la Visita: en Visita hecha a la provincia de Chucuito por Garci Diez de San Miguel en 1567. Documentos regionales para la Etnología y Etnohistoria Andinas. Tomo 1. Lima, Perú: Casa de la Cultura del Perú.

Núñez, E. y Petersen, G. (2002). Alexander Von Humboldt en el Perv. Diario de viaje y otros escritos. Lima: Fondo Editorial Banco Central del Perú.

Núñez, L. (1986). Balsas prehistóricas del litoral chileno: grupos, funciones y secuencia. Boletín del Museo Chileno de Arte Precolombino, 1, 11-35.

O’Phelan, S. (2010). Humboldt, el Perú y sus recursos naturales: entre la plata y el guano. Revista Internacional de Estudios Humboldtianos, XI(20), 75-84.

O’Phelan, S. (2012). Entre la Intendencia de Arequipa y la de Lima: El Andaluz Bartolomé María de Salamanca y su gestión en el virreinato del Perú. En Vila, E. y Lacueva, J. (Coords.). Mirando las dos orillas: intercambios mercantiles, sociales y culturales entre Andalucia y América (pp. 541-562). Sevilla: Fundación Buenas Letras.

Pagden, A. (1997), Señores de todo el Mundo: Ideologías del Imperio en España, Inglaterra y Francia (en los siglos XVI, XVII y XVIII). Madrid: Editorial Península.

Pestle, W. J., Torres-Roueff, C., Hubbe, M., Santana, F., Pimentel, G., Gallardo, F. y Knudson, K. J. (2015). Explorando la diversidad dietética en la prehistoria del desierto de Atacama: un acercamiento a los patrones regionales. Chungara. Revista de Antropología Chilena, 47, 201-209.

Pinto, J. (1990). La caldera del desierto. Los trabajadores del guano y los inicios de la cuestión social. Proposiciones, 19, 123-141.

Rivero, M. (1827). Memoria sobre el guano de pájaros del Perú. Lima: Imprenta de la Instrucción Primaria.

Rostworowski, M. (1981). Recursos naturales renovables $y$ pesca, siglos XVI y XVII. Historia Andina 8, Lima: Insti- tuto de Estudios Peruanos.

Rostworowski, M. (1986). La región del Colesuyo. Chungara. Revista de Antropología Chilena, 16/17, 127-135.

Salazar, C. (2009). Minería y moneda en la época colonial temprana. En Contreras, C., Noejovich, H., Salazar, C., Suárez, M., Glave, L. y Salas, M. (Eds.). Compendio de historia económica del Perú II: Economía del periodo colonial temprano (pp. 109-228). Lima: BCRP; Instituto de Estudios Peruanos.

Santoro, C., Hidalgo, J. y Osorio, A. (1987). El estado Inka y los grupos étnicos en el sistema de riego de Socoroma. Chungara, 19, 71-92.

Téllez, E. (1986). Producción marítima, servidumbre indígena y señores hispanos en el partido de Atacama: Un documento sobre la distorsión colonial del tráfico entre el Litoral Atacameño y Potosí. Chungara, 16/17, 159-165.

Trelles, E. (1982). Lucas Martínez Vegazo: Funcionamiento de una encomienda peruana inicial. Lima, Perú: Pontificia Universidad Católica del Perú.

Vázquez de Espinosa, A. (1948 [1636]). Compendio y descripción de las Indias Occidentales. Ch. Upson Clark (Ed.). Washington: Smithsonian Institution.

Villalobos, S. (1979). La economía de un desierto. Tarapacá durante la Colonia. Santiago: Ediciones Nueva Universidad.

Willey, G. (1971). An Introduction to American Archaeology Vol. 2: South America. Englewood Cliffs: Prentice Hall.

Zolezzi, M. (1993). La destrucción del Bosque de La Soledad durante el Ciclo Salitrero de Tarapacá. Camanchaca, $14,6-8$.

\section{Fuentes manuscritas utilizadas}

Archivo Arzobispal de Arequipa, (Arequipa). Legajo Arica, Codpa, Años: 1650-1891, Expediente 4- enero de 1804.

Archivo Digital de la Legislación del Perú, Decreto 18 de marzo, 1822

Archivo Digital de la Legislación del Perú, Decreto 6 de septiembre, 1833. 
Archivo Digital de la Legislación del Perú, Decreto 5 de agosto, 1833

Archivo General de Indias (Sevilla), Charcas, Legajo 80.

Archivo General de Indias (Sevilla), Charcas, Legajo 92.

Archivo General de Indias (Sevilla), Lima 250, No 6. Información: Manuel Rodríguez, 1658.

Archivo General de Indias (Sevilla), Casa de Contratación 498B, N 5 . Bienes de Difuntos de Lorenzo Báez y otros, 1606.

Archivo General de Indias (Sevilla), Lima 895. Oficiales Reales v/s Egan.

Archivo General de la Nación (Lima), Fondo Derecho Indígena y Encomienda, Cuaderno 15, legajo 2, años 1570 y 1571 .
Archivo Histórico Nacional (Santiago), Fondo Notarial de Arica, Volúmenes 2 y 5.

Archivo Histórico Nacional (Santiago), Fondo Judicial Administrativo de Arica, Legajos 3, 5 y 8.

Archivo Histórico Nacional (Santiago), Fondo Notarial de Arica, Vol. 37.

Archivo Histórico Nacional (Santiago), Fondo Judicial de Iquique, causas civiles. Legajo 291.

Archivo Histórico Nacional (Santiago), Fondo Intendencia de Tarapacá, Volumen 91.

Archivo del Ministerio de Relaciones Exteriores del Perú (Lima), Legajo 415, 1804; Cuaderno de la Santa Visita a la Doctrina de San Martín de Codpa. 